\title{
An Ontology Co-design Method for the Co-creation of a Continuous Care Ontology
}

\author{
Femke Ongenae ${ }^{\mathrm{a}, *}$, Pieter Duysburgh ${ }^{\mathrm{b}}$, Nicky Sulmon ${ }^{\mathrm{c}}$, Mathijs Verstraete ${ }^{\mathrm{c}}$, Lizzy Bleumers ${ }^{\mathrm{b}}$, \\ Saar De Zutter ${ }^{\mathrm{d}}$, Stijn Verstichel ${ }^{\mathrm{a}}$, Ann Ackaert ${ }^{\mathrm{a}}$, An Jacobs ${ }^{\mathrm{b}}$, and Filip De Turck ${ }^{\mathrm{a}}$ \\ ${ }^{a}$ Department of Information Technology (INTEC) \\ Ghent University-iMinds \\ Gaston Crommenlaan 8, bus 201, 9050 Ghent, Belgium \\ E-mail: \{Femke.Ongenae,Stijn.Verstichel,Ann.Ackaert,Filip.DeTurck\}@intec.ugent.be \\ ${ }^{\mathrm{b}}$ Research Centre for Studies on Media, Information and Telecommunication (SMIT) \\ Brussels University (VUB)-iMinds \\ Pleinlaan 2, 1050 Brussels, Belgium \\ E-mail: \{Pieter.Duysburgh,LBleumer,An.Jacobs\}@vub.ac.be \\ ${ }^{\mathrm{c}}$ Centre for User Experience Research (CUO) \\ K.U. Leuven-iMinds \\ Parkstraat 45, bus 3605, 3000 Leuven, Belgium \\ E-mail: \{Nicky.Sulmon,Mathijs.Verstraete\}@soc.kuleuven.be \\ ${ }^{\mathrm{d}}$ Televic Healthcare $N \mathrm{~V}$ \\ Leo Bekaertlaan 1, 8870 Izegem, Belgium \\ E-mail:S.DeZutter@televic.com
}

\begin{abstract}
Ontology engineering methodologies tend to emphasize the role of the knowledge engineer or require a very active role of domain experts. In this paper, a participatory ontology engineering method is described that holds the middle ground between these two 'extremes'. After thorough ethnographic research, an interdisciplinary group of domain experts closely interacted with ontology engineers and social scientists in a series of workshops. Once a preliminary ontology was developed, a dynamic care request system was built using the ontology. Additional workshops were organized involving a broader group of domain experts to ensure the applicability of the ontology across continuous care settings. The proposed method successfully actively engaged domain experts in constructing the ontology, without overburdening them. Its applicability is illustrated by presenting the co-created continuous care ontology. The lessons learned during the design and execution of the approach are also presented.
\end{abstract}

Keywords: ontology engineering, co-design, continuous care, eHealth, participatory

\section{Introduction}

\subsection{Background and objective}

Close collaboration between domain experts and ontology engineers is required to construct an accurate and useful ontology, which formally captures the knowledge within a particular domain. However, the survey of Simperl et al. (2010) found that current ontology engineering methodologies are very generic when it comes to issues of knowledge elicitation from domain experts. The methodologies acknowledge there exists an imperative need for a close interaction between domain experts and ontology engineers, but extensive studies on which techniques should be used for this are largely missing.

In this paper, an ontology engineering approach is described that aims at involving the domain experts in each step of the ontology life cycle without asking them to construct the ontology themselves or attribute a large amount of their time. The approach acknowledges that domain experts are not ontology engineers

\footnotetext{
*Corresponding author: Femke Ongenae, Ghent University - iMinds - IBCN, Gaston Crommenlaan 8, bus 201, 9050 Ghent, Belgium.
} 
and vice versa. To reach this goal, user-driven and participatory methods and tools are employed. The rationale behind this approach is that it increases the acceptance of ontology-driven technologies and facilitates their appropriation by the domain experts. It encourages users to feel in control of the ontology, continue to adapt it and to thus increase its accuracy.

The objective of this paper is twofold. On one hand, the process we have designed to realize a participatory ontology engineering method is discussed. A series of workshops is described that were organized to actively involve domain experts. The instruments that were used to unite all the insights gained during these workshops and how these were translated into the ontology are presented. On the other hand, the continuous care ontology, which resulted from applying the method, is presented.

The following specific research questions are addressed:

- RQ1: How to involve users in the creation of an ontology without overburdening them?

- RQ2: How to reach a cross-institutional validity of an ontology?

This paper elaborates on previous publications about this research (Bleumers et al., 2011; Ongenae et al., 2011c) by concentrating on the whole ontology development process by including later stages of the ontology construction, i.e., the workshops that have addressed the cross-institutional validity of the ontology. As such, a reflection on the whole process was possible.

\subsection{Related work}

\subsubsection{Ontology engineering}

An ontology formally describes the concepts in a domain, their attributes and their relations. It can also contain classification rules. This standardized representation of the semantics of a domain can then be used to exchange data and its attached domain model. In this way an ontology encourages re-use, communication, collaboration and integration (Gomez-Perez et al., 2003). Ontology engineering is described as (Gomez-Perez et al., 2003): "the set of activities that concern the ontology development process, the ontology life cycle, and the methodologies, tools and languages for building ontologies". Pinto and Martins (2004) derive five stages for building an ontology:

1. Specification: The purpose and the scope of the ontology are identified.

2. Conceptualization: A conceptual model of the ontology is constructed. It consists of the different concepts, relations and properties that can occur in the domain. This step can include studying other existing ontologies that can be reused.

3. Formalization: The conceptual model is translated into a formal one, e.g., by adding axioms that restrict its possible interpretations.

4. Implementation: The formal model is implemented in a knowledge representation language, e.g., the Web Ontology Language (OWL) (McGuinnes and Van Harmelen, 2004).

5. Maintenance: The implemented ontology has to be constantly evaluated, updated and corrected. The previous steps can be used for this.

There are also activities that should be performed during the whole life cycle, namely knowledge acquisition, evaluation and documentation. However, it is important to note that not all stages are widely practiced or strictly separated in practice. Various ontology engineering methodologies have been proposed that describe methods to realize the goals of each of these stages. A comprehensive overview of the current state of the art in ontology engineering can be found in Simperl et al. (2010). The well-known methodologies can be divided into two major groups depending on the role the domain experts play.

The first group of methodologies, such as TOVE (Grüninger and Fox, 1995), ENTERPRISE (Uschold and King, 1995), OTK (Sure et al., 2009) and METHONTOLOGY (Fernández et al., 1997), emphasize the role of the knowledge engineer. Domain experts are only, mostly passively, involved during the specification phase to discuss the scope, requirements and use of the ontology. No methods or tools are offered to empower the domain experts to actively participate in the ontology life-cycle. This negatively influences 
the acceptance of the ontology, its accurate reflection of the domain. It also hinders domain experts in having control over the knowledge flow in their environment and adapt it to their needs.

The second group, such as HCOME (Kotis and Vouros, 2006) and DOGMA (Spyns et al., 2008), put the domain experts at the center of the ontology engineering process. User-friendly and collaborative tools are offered that allow them to construct, merge and discuss their own ontologies. The knowledge engineer delivers (technical) support in this process. However, these approaches thus require domain experts to make a considerable time-investment and acquire skills to construct the ontology themselves. This is a considerable effort, one that is not always feasible for domain experts.

As can be seen, the existing approaches take a rather opposed stance when it comes to including domain experts in the ontology life cycle. In this paper, an ontology co-creation approach is described that finds the middle ground between the two extremes. Co-creation has been described as "any act of collective creativity that is shared by two or more people" (Sanders and Stappers, 2008). When integrated in a design process, it is also called co-design (Bassetti, 2012). Co-design has its roots in participatory design (Kensing and Blomberg, 1998), an approach towards computer systems design in which the people destined to use the system also play a critical role in designing it (Schuler and Namioka, 1993). Ontology co-creation thus refers to a creative, continuous involvement of stakeholders, i.e., (in)direct users, and ontology engineers in the ontology engineering process. As such, the ontology engineers and domain experts become equal partners and contributors in the ontology creation process. Kuziemsky and Lau (2010) see ontology cocreation as the key to the challenge of creating an ontology that is both accurate and useful. Some of the methods used in this research are also closely related to Digital Action Research (Martensson and Lee, 2004) in which the researchers do not attempt to teach scientific theory to domain experts, but instead try to speak the language of these practitioners and accept them as experts on their domain and its problems.

Some of the co-creation methods proposed in this paper resemble those used by the agile software development community (Martin, 2002). These software engineering methods also put a strong emphasis on continuously involving the users to determine the goals and requirements of the software under development. As such, the proposed method is most closely related to the agile ontology engineering methods proposed in Copeland et al. (2012) and Auer and Herre (2007). However, the ontology co-creation approach introduced in this paper elaborates on these methods by proposing workshops that do not require a large time investment from the domain experts. Moreover, emphasis was put on finding techniques and tools that do not require the stakeholders to interact with a computer or become ontology engineers themselves.

\subsubsection{Ontology-based pervasive healthcare}

As pervasive computing (Satyanarayanan, 2001) continues to form one of the most exciting trends of information technology, it also poses an interesting challenge to manage and transform data from unobtrusive technology into intrusive information. Future pervasive applications are envisioned to adapt their behavior by interpreting various contexts of an environment and its users. Such contextual information may often be ambiguous and heterogeneous, which makes the delivery of unambiguous context information to applications extremely challenging (Roy et al., 2010). The growing interest in context-aware applications, which are adaptive and capable of acting autonomously on behalf of users, is spreading across domains such as education, transportation, manufacturing and healthcare (Burgelman and Punie, 2006).

When looking at healthcare, pervasive computing has led to the idea of the ambient intelligent care room of the future (Punie, 2005; Ongenae et al., 2010). All the heterogeneous data captured in the room by numerous collaborative devices, i.e., sensors, wireless devices and input from caregivers, are combined to support both the caregivers and care receivers, i.e., patients or residents, in carrying out their daily activities and tasks. However, this vision is far from current reality. Today, caregivers mainly coordinate, manage and consult the single devices themselves. No integration is done of the several sources caregivers use for consulting and entering data (Tentori et al., 2009). Consequently, caregivers lose time, miss out on potential insights about care receivers and lack a general overview of the current situation.

The definition and use of ontologies to tackle these integration issues is an active research field, as it has been recognized that ontology-based systems can be used to improve the management of complex health systems (Valls et al., 2010). Kuziemsky and Lau (2010) observe how little research has been done on 
ontology co-creation in (health)care, a field which would greatly benefit from high-quality and practical ontologies. Indeed, caregivers are faced with a vast amount of information that they need to integrate and prioritize. By implementing a context-aware, ontology-based framework, care tasks could be automated to alleviate caregivers' workload. The first steps towards such frameworks can be found in Paganelli and Giuli (2011); Ongenae et al. (2011b, 2013); Fook et al. (2006); Zhang et al. (2005) and Ko et al. (2007).

Ontologies are widely accepted within the eHealth domain, e.g., Galen Common Reference Model (Rector et al., 2003) or the Gene Ontology (Blake and Harris, 2008). Ongenae et al. (2011a) give an overview of the most relevant, well-known and well-developed eHealth ontologies. However, little work has been done on the development of ontologies to support continuous care.

\subsection{Definitions and terminology}

Before going into the description of the approach, a few concepts are introduced that formed the common thread throughout the process and are thus essential for understanding how the objectives were attained.

\subsubsection{High and low level ontologies}

We aimed at developing a continuous care ontology that would be applicable in both care residences (care settings) as in hospitals (cure settings). To achieve this, the ontology had to be subdivided into a high-level and several low-level ontologies. The high-level ontology describes concepts and relations that apply for both care and cure settings. Concepts and relations that are specifically related to a care or a cure setting were included in the low-level ontology for this domain.

\subsubsection{Dynamic nurse call system}

To achieve a deeper reflection on the concepts and axioms captured in the ontology, one future care application was chosen to be developed as a prototype. This chosen prototype was a dynamic nurse call system. The reason for this choice is motivated in Section 2.2.

Traditional nurse call systems are static as calls are made by buttons fixed to a wall and the nurse call algorithm consists of predefined links between rooms and caregivers' beepers (Miller et al., 1997). The current context is not taken into account to assist users in making calls, assign caregivers to calls or detect hazardous situations for which calls should be made. The beepers also give the caregivers limited information about the current situation and call and do not allow feedback to be given to the caller.

The dynamic, ambient-intelligent nurse call system developed in this research (Ongenae et al., 2011b) provides each care receiver and caregiver with a badge to locate this person. Each badge also has a call button allowing care receivers and staff to walk around freely and still make calls. When the ambientintelligent system receives or generates a call, a decentralized algorithm for call triage finds the best-suited caregivers to answer it. For this, the algorithm makes use of all kinds of heterogeneous sensor data, e.g., vital parameters and light sensors, and context and user-specific parameters, e.g., locations, qualifications, occupation and trust relations, that are captured in the continuous care ontology, which was developed using the method described in this paper. The novel nurse call system is also able to automatically generate new calls based on this data. More information about this prototype can be found in Ongenae et al. (2012).

\subsubsection{Innovation binder}

This research was performed as part of the ACCIO (Ambient aware provisioning of Continuous Care for Intra-muros Organizations) (Ongenae et al., 2010; ACCIO Project, 2012) project which aimed at developing an intelligent, context-aware framework, which exploits and integrates the available heterogeneous data by employing a continuous care ontology to support caregivers and care receivers in their daily activities. In order to keep an overview of the project objectives, i.e., development of the ontology, the framework and the future care application, and their interrelatedness, the so-called innovation binder was used as a central coordination instrument. The development of the innovation binder was an iterative, evidence-based process, involving all the stakeholders and incorporating all the insights and research results obtained during the various steps of the participatory development process.

The innovation binder contains a set of carefully constructed personas (Pruitt and Adlin, 2006). Personas communicate common attitudes, desires, behaviors and frustrations for a particular user group. Their main 
advantage is that they allow the feeling of real empathy for the user group, as they put a human face to a list of requirements. The innovation binder also contains a sunny-day scenario. A scenario is a short story that describes the hypothetical use of a system to help develop a detailed and shared understanding of the context and activities of the users. The scenario is sunny-day because it is an ideal scenario in which the technology, e.g., the context-aware system, the sensors and actuators, optimally supports the needs of the users and the context, unconstrained by the current technological possibilities. The scenario thus brings together the continuous care concepts that all partners envision, the implications of the scenario for all project partners, and the process that was followed to attain the current iteration of the scenario. The sunny-day scenario consists of a number of scenes in which the actions of the personas are described in such a manner that the functionality of the continuous care concepts become clear. In the project, the innovation binder serves as a boundary object (Star and Griesemer, 1989), an instrument to unite both technical and user researchers and to create a common focus for all partners involved in the project.

\section{Ontology co-creation method}

In this section, the steps of the participatory ontology engineering method are described that were taken to go through all the stages that Pinto and Martins (2004) have identified for ontology development. These steps are summarized in Figure 1. The research team mentioned in these phases consists of both ontology engineers and social scientists. The descriptions of the steps are split up into the following parts:

- Objective: explaining the intended goal

- Participants: detailing the profiles of the people participating

- Method: conveying the methods that were followed during the workshop or observations

- Analysis: explaining how the output is structured, processed and analyzed

- Results: presenting the results obtained

- Reflections: reflects on the approach followed and results obtained with respect to the objective

\subsection{Composing a stakeholder group}

A representative stakeholder group was composed to ensure all relevant perspectives were included in the ontology creation process as well as create a stage where ontology engineers could interact with domain experts and social scientists. The group consists of:

- Ontology engineers with a computer science background who have been involved in eHealth projects.

- Targeted end-users, i.e., nurses, doctors and residential caregivers.

- Professionals working for the healthcare industry.

- Social scientists experienced with conducting user research.

There was a big difference in the extent to which the stakeholders 'believed' in the project. Some were very skeptical, which is important to ensure critical thinking. Others felt strongly positive and took on the role of advocates of the project within their organizations, creating goodwill among their colleagues. Finding a good balance between skeptical and enthusiastic stakeholders is important. However, actively pursuing this balance might prove difficult.

To persuade domain experts to actively participate in the workshops, different methods were used. One of the observed settings received government funding to take part in the project. Other organizations freed up time in the work schedule of their staff such that they could attend the workshops. In return we offered some expert advice, e.g., an analysis of the information flow or state-of-the-art software tools that could be integrated into their processes. We also tried to reduce the amount of time that had to be invested by the stakeholders by, e.g., keeping the workshops short and small or organizing them at the workplace of the stakeholder. Moreover, the workshops were often organized in conjunction with other exhibits or events that the stakeholders were eager to attend, e.g., a visit to the Patient Room of the Future (PRoF) (PRoF Consortium, 2013). Sometimes incentives were given, e.g., gift cards. Teachers and students, i.e., studying 


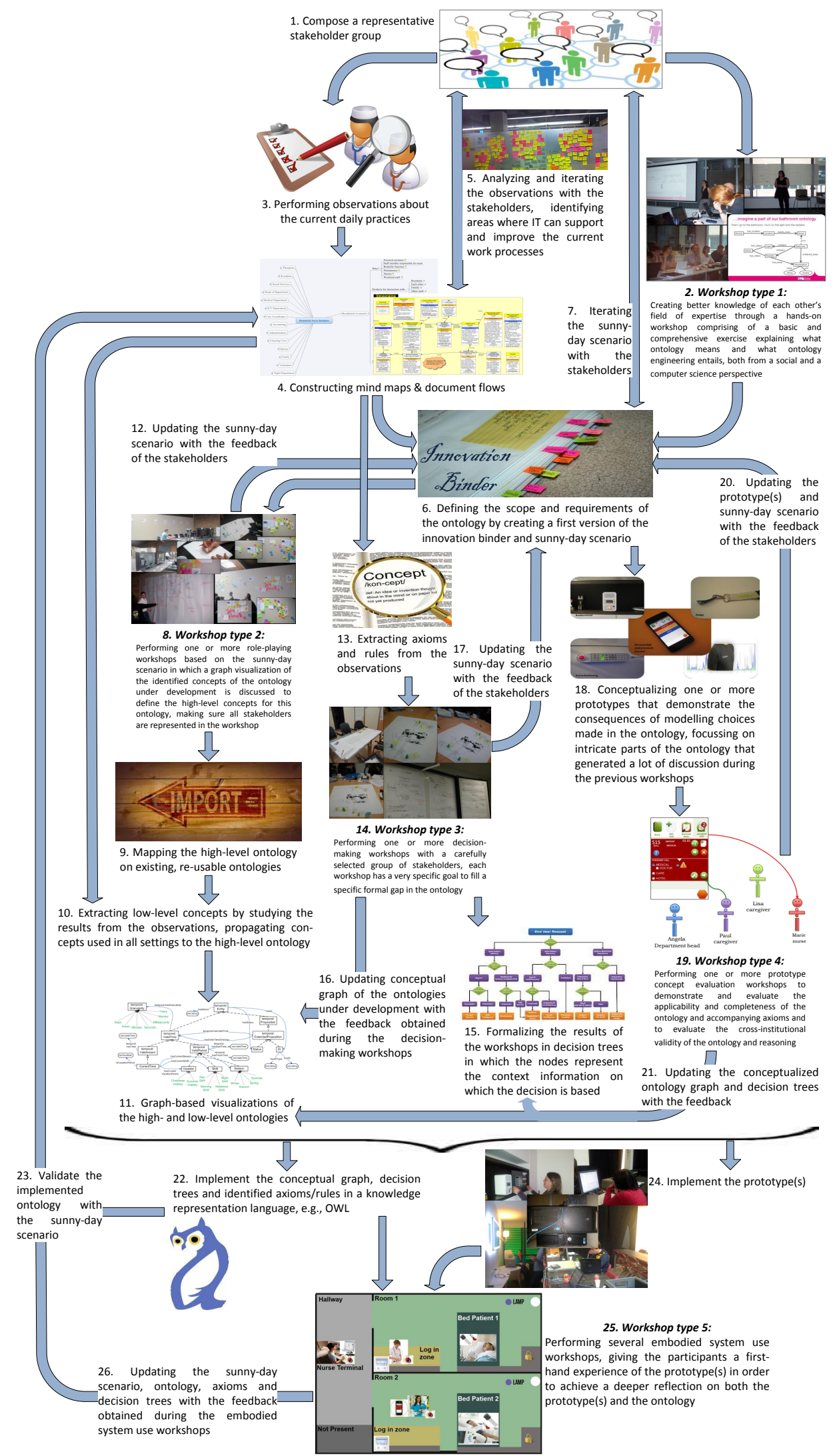

Figure 1 . The various steps of the proposed participatory ontology engineering method 


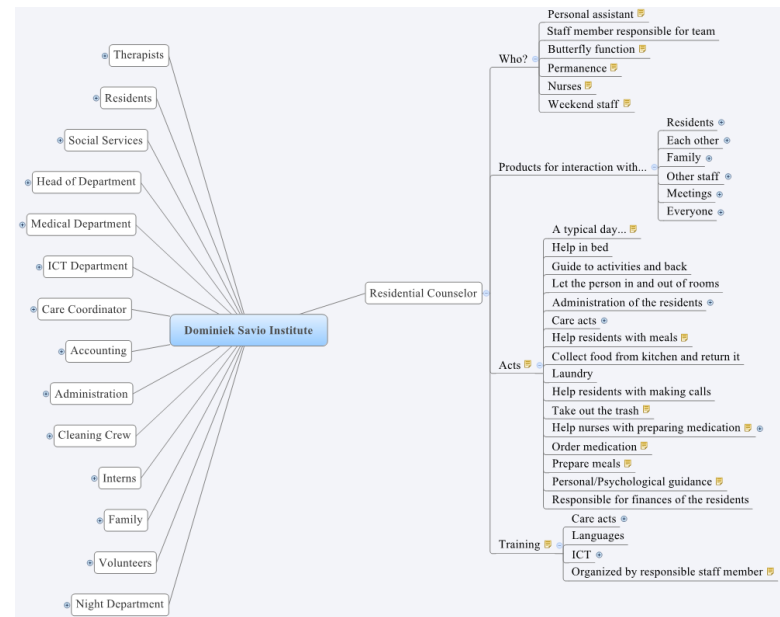

(a) Example mind map, summarizing the observations at Dominiek Savio Institute

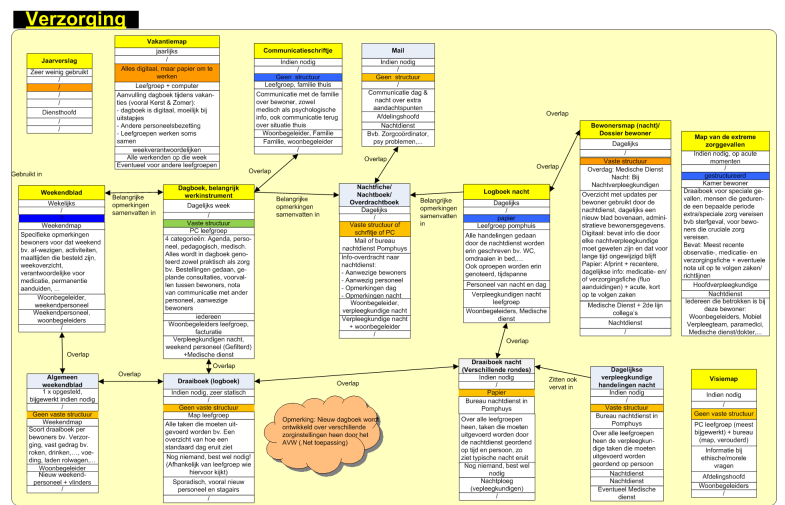

(b) Part of the document flow, visualizing the information being exchanged at Dominiek Savio Institute

to become nurses, sometimes participated in the workshops as part of their courses. We also found that once stakeholders participated in a workshop, it was often easy to persuade them to attend the following ones as they were eager to see the end result. The enthusiastic stakeholders played an important role in keeping the remainder of the group motivated.

\subsection{Observations at institutionalized settings of care}

\subsubsection{Objective}

The objective is to get a first understanding of the context the ontology would have to describe and how the provision of continuous care can be optimized.

\subsubsection{Participants}

Two major types of institutionalized care settings were identified, namely residential (focus on caring for residents) and hospital care (focus on curing patients). A representative Flemish institution from each closely collaborated in the project, namely Dominiek Savio Institute (2013), which provides residential care to people suffering from cognitive and physical impairments, and OLV Hospital Aalst (2013).

\subsubsection{Method}

The social scientists together with ontology engineers performed a contextual inquiry (Beyer and Holtzblatt, 1997) in the two settings. 12 day shifts and two evening shifts during two weeks and six shifts during three days were observed in the care residence and hospital respectively. During every shift, two researchers were present to observe the daily care processes. Representatives of each role, e.g., caregiver or therapist, were followed and informally interviewed. The ethnographic interviews were casually performed by the researchers while they were observing the domain experts by inquiring into the actions they were performing, their motivations, the struggles they faced, etc. The observations were filmed and extensive notes were also made. Additionally, all documents used in the institution were listed and their flow in the institution was mapped.

\subsubsection{Analysis}

The researchers processed the notes and film separately and synthesized the insights in extensive mind maps (XMind, 2013), as illustrated in Figure 2a. As visualized in Figure 2b (in Dutch), Document flows were constructed to get a clearer view of all the information being exchanged, either analog or digital. It also describes the properties of the documents, i.e., content, aim, author(s), target audience, location and relationships to other documents. The mind maps and document flow were iteratively discussed amongst the researchers and were evaluated and validated multiple times with stakeholders from the institutions, who were not necessarily involved in the observations. 


\subsubsection{Results}

Representatives from the stakeholder group processed, discussed and evaluated the mind maps and document flows to identify areas where IT could ideally support care receivers and caregivers in their daily activities. For this evaluation, a technique was used, which is closely related to planning poker (Grenning, 2002) from agile software development. Problem areas and possible solutions were captured on post-its during brainstorm exercises. Next, each participant received a number of votes to put towards the problems $\&$ solutions, which he or she perceived as most important or desirable. The post-its were ranked according to the number of votes. From the top ranked ideas, the ones were selected that were feasible within the time-frame of the project, aligned most with the project's aim and expectations of the partners.

As a result, two areas for improvement were selected: information integration \& data provisioning at the point of care and a dynamic nurse call system. The first can be summarized as providing the right information, at the right time, at the right place for the right person. Consequently, information should be integrated, filtered and prioritized based on the current context. Moreover, mobile services should support data input and requesting data at the point of care. As explained in Section 1.3, a dynamic nurse call system was chosen to be developed to demonstrate the possibilities of an ontology-based, context-aware application as it tackles both identified areas for improvement.

The insights in the mind maps and document flows were combined with this research objective to write a first version of the sunny-day scenario and innovation binder. This defines the scope and purpose of the ontology. The most important created persona was Erik, who lives at a care residence, has Duchenne disease, is dependent on a wheelchair and desires more autonomy. Personas were also created for Erik's family, staff at the care residence and associated hospital. The sunny-day scenario describes that Erik becomes unwell in his residential care setting and is transported to a hospital for treatment. The care for Erik in both settings is supported by the dynamic nurse call system, which uses the ontology to gather information and infer knowledge.

\subsubsection{Reflections}

Conducting the observations by social scientists and ontology engineers ensured a 'naive' perspective on the practice of giving care. While domain experts have a much deeper understanding of the domain than observers can achieve after a few days, or even weeks, they also tend to overlook the obvious. A combination of experts and laymen is thus recommended.

Due to the combination with the constant, informal interview method, the observations were also somewhat time consuming. As the goal of the methodology is not to overburden the domain experts, the observation period was kept quite short. However, this was mediated by the experience of both the social scientists and ontology engineers in the healthcare domain and the iterative processing of the mind maps and document workflows with the domain experts. As these mind maps and workflows reached a consensus after a while and no more obvious gaps were reported by the stakeholders, we felt that the amount of performed observations was sufficient.

The observations and ensuing discussions were a good starting point as they allowed us to construct drafts of the innovation binder, define the scope and purpose of the ontology and determine the focus.

\subsection{Workshop type 1: Introducing ontologies}

\subsubsection{Objective}

The goal is to educate the stakeholders about ontologies and ontology engineering, discuss how to jointly design ontologies in the domain of institutionalized care and create a shared view on ontologies.

\subsubsection{Participants}

22 members of the stakeholder group participated, including targeted end-users from the observed settings. 


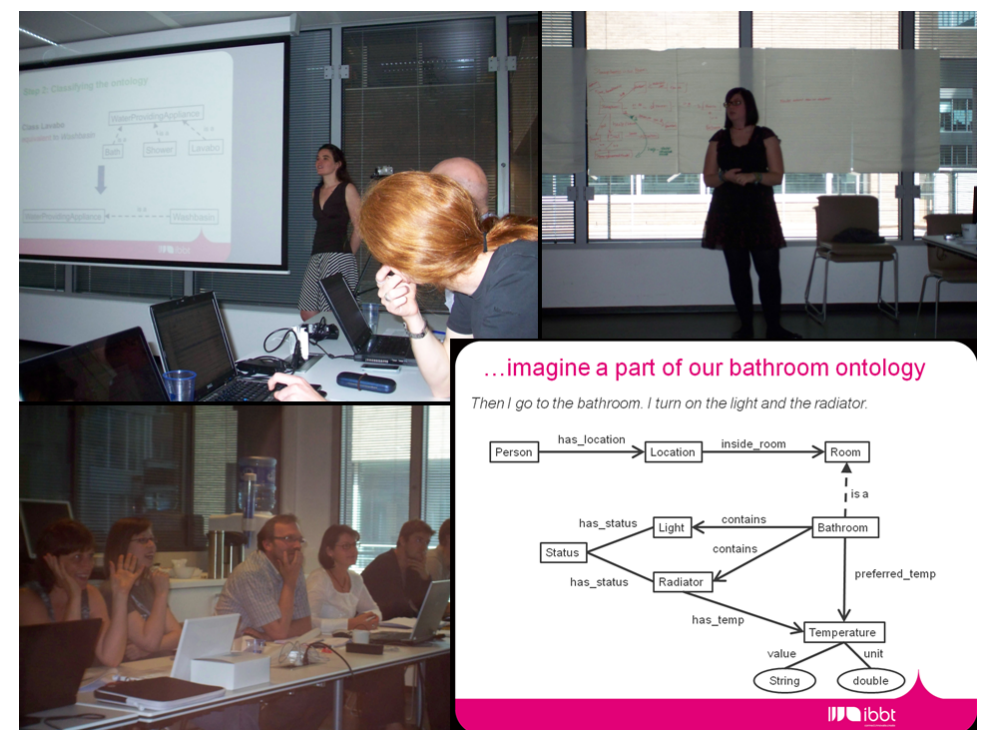

Figure 2. Impressions of workshop 1: Introducing ontologies

\subsubsection{Method}

The half-day workshop was organized by ontology engineers and social scientists. It started with a description of what an ontology is, both from a social science and ontology engineering perspective. To participants' prepared a textual description of a bedroom. We presumed that this would be an important space where we want the ontology-based system to operate in a residential care and hospital environment. Participants had to mark in this text which sentences and words were important to define a bedroom. This made clear that different perceptions exist of what a bedroom is and that a common agreement is needed in order to create a model or ontology. The ontology engineer then restructured the terms as concepts in a graph while explaining essential ontology engineering terminology. For the latter, an example ontology of a bathroom was used, as shown in Figure 2. It was shown how this graph could form the basis for an ontology, and how defining constraints and relations can limit the different interpretation of the concepts. It was also illustrated how an application can be built using this ontology. Finally, a group discussion was started on how these ontologies can be used to automate processes in institutionalized care.

\subsubsection{Analysis \& results:}

This workshop had no tangible results, since it was mainly informative. The participants did indicate their understanding of the project in general and of ontologies in particular had thoroughly improved, to the extent that they would even be able to explain the concept of ontologies to others.

\subsubsection{Reflections}

The participants were generally enthusiastic about the hands-on exercises and discussion that ensued. Learning to understand each other is an essential step in interdisciplinary research and co-creation processes as the group diversity and the background knowledge is very different. The workshop created a common ground and purpose for all project partners, such that a better integration of concepts and views could be initiated in the subsequent development steps. This enabled the stakeholders to step up as project advocates and motivate other stakeholders to take part in the subsequent workshops.

The researchers considered repeating this workshop with only targeted end-users as this might give them additional insights into why the workshops would be conducted and which results we wanted to obtain. However, we refrained from doing so because this might be too demanding on the part of the domain experts and would resemble the HCOME approach, something we wanted to avoid. Moreover, we wanted to evaluate how we could construct an ontology with domain experts, without them needing to know what 'ontology' means. 


\subsection{Workshop type 2: Scenario role-play}

\subsubsection{Objective}

The aim is to create an ontology that is abstract enough to capture the care practices in all continuous care settings. However, it should remain specific enough to build practical applications on it. Therefore, the goal of this workshop was to construct the basis for a high-level ontology.

\subsubsection{Participants}

To capture high-level knowledge, a diverse group was invited consisting of 18 participants from various hospitals and care residences and with different roles, ranging from care giving to managerial functions.

\subsubsection{Method}

The workshop was organized in PRoF, which is a high-fidelity mock-up of a near-future patient room and hallway in a hospital and an apartment mimicking a homecare setting. PRoF integrates innovations from soft- and hardware developers as well as furniture. The workshop proceeded in four steps:

1. Storyboard: A short introduction of the ACCIO project and its goals was given in layman's terms, e.g., avoiding the term ontology. The first version of the sunny-day scenario was visualized in a storyboard, which was hung on the wall as shown in Figure 3. The storyboard formed the common thread in the workshop and served as a point of reference during group discussions.

2. Role-play: The participants took turns in playing out scenes from the storyboard within PRoF. Persona, e.g., an impatient care receiver, and situation, e.g., busy night, cards informed the participants about the context and character they would be playing. The other participants observed a live feed of the role-play on monitors and noted down issues or remarks.

3. Reflection: After each role-play, a group discussion took place. As shown in Figure 3, the noted down issues and remarks and points raised during the discussions were visualized on the storyboard with post-its or drawings. They visualized perceived problems, e.g., difficult for care receiver to alert a caregiver, or opportunities, e.g., automatic fall detection.

4. Modeling: Two ontology engineers followed the performances and discussions in the background, translating its output to a graph representing the high-level ontology concepts (nodes) and relations (vertices). As shown at the bottom of Figure 3, the graph was drawn on clearly visible posters next to the storyboard so that all stakeholders could see its evolution and provide feedback.

\subsubsection{Analysis}

The notes and drawings attached to the storyboard were clustered per scene. These clusters were analyzed in a research team meeting to identify general themes, e.g., the importance of roles and competences and desired sensors and related data extraction, which were integrated in the ontology.

\subsubsection{Results}

The workshop resulted in a new iteration of the innovation binder, taking into account the feedback of the stakeholders. A first version of the high-level ontology was constructed, as illustrated in Figure 4. Six sub-domains were identified, namely information pertaining to tasks \& processes, person profiles, roles $\&$ competences, medical context, sensor observations, time and general concepts. The most important concepts within these sub-domains were identified (69 concepts in total). Next, the ontology engineers integrated the information captured in the mind maps and document flows in this ontology. Moreover, an investigation into existing, re-usable ontologies was performed. The suitable ones were imported, e.g., the OWL-S Process ontology (Martin et al., 2004) and SWRLTemporalOntology (O'Connor and Das, 2010).

Two low-level ontologies were conceptualized based on the document flows and mind maps, containing concepts specific to residential care (focus on care) and hospital (focus on cure) settings, e.g., roles, competences, tasks and profiles. These low-level concepts are always subconcepts of concepts in the high-level ontology. The two low-level ontologies were compared to identify common concepts used with the same meaning. These concepts were moved to the high-level ontology. The resulting ontologies are discussed in Section 3. 


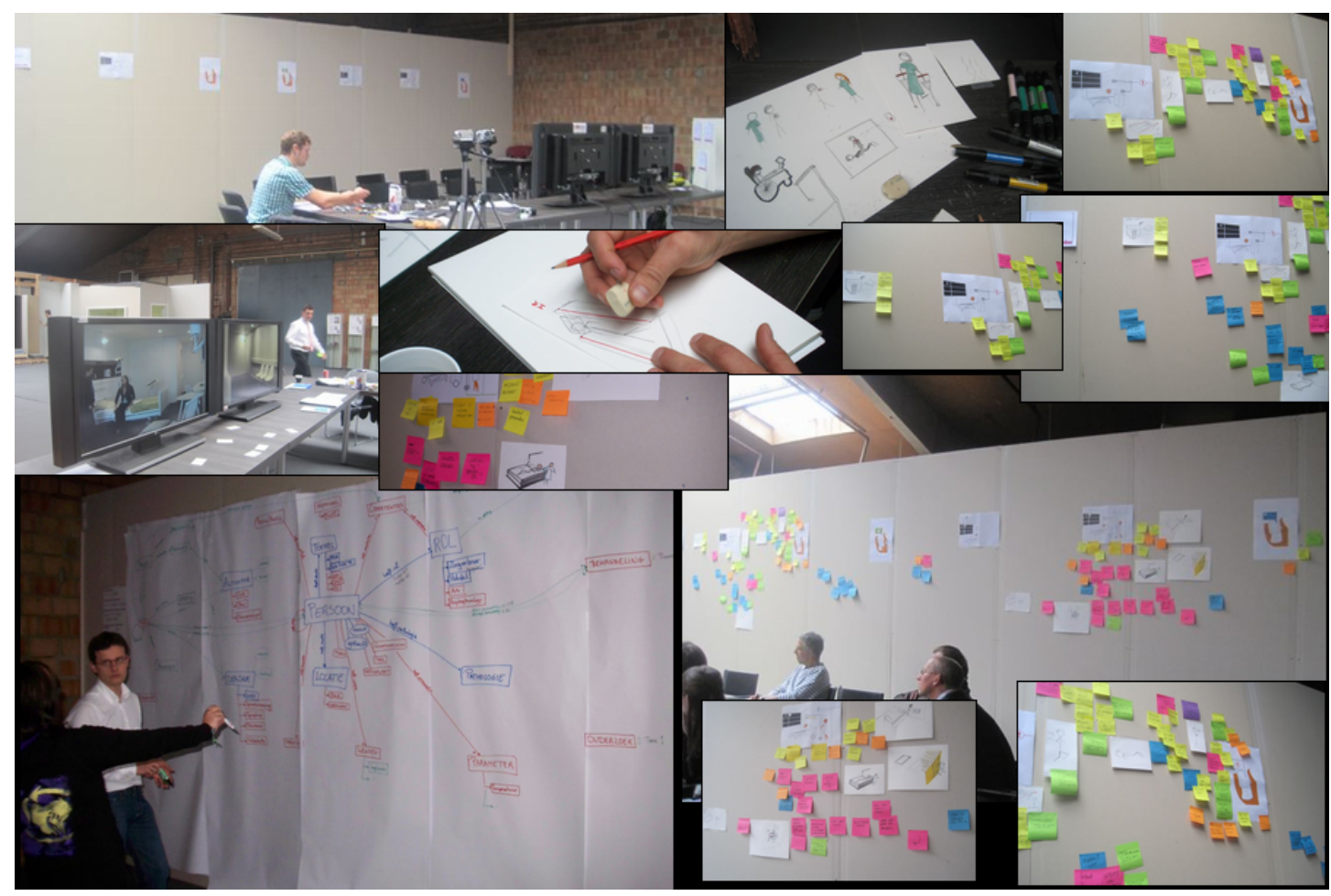

Figure 3. Impressions of workshop 2: role-playing at the PRoF

\subsubsection{Reflections}

Although this workshop helped to validate and extend the innovation binder, the process of constructing a high-level ontology was not fully satisfactory. Discussions covered too many topics and a consensus was rarely reached, making it hard to evaluate if a concept had the same meaning for the different stakeholders. It was also difficult to formalize or pick up the different relations that existed between concepts. In retrospect, the lack of consensus was however not problematic as it became clear that this is an indication that the concepts where no agreement could be found, should not be part of the high-level ontology.

After the workshop, the participants filled in a formal, anonymous evaluation form. The mixture of profiles ensured that the participants evaluated the workshop as very interactive and an enriching experience. However, it was deemed a little too time consuming. The researchers echoed the latter remark. The obtained results were useful, however not in relation to the invested amount of (preparation) time.

In hindsight, the broad and time-consuming discussions were also a consequence of the large number of participants. As not all participants took part in workshop 1, they did not have much insight in the project's objectives and ontology engineering. The lack of contextual information combined with the large group size probably explains the lack of collaboration between the participants and ontology engineers, who rather observed the activities than co-created the ontology with the participants.

To summarize, it seems that this workshop is more suitable for validation than conceptualization.

\subsection{Workshop type 3: Decision-making}

\subsubsection{Objective}

At this point, the ontology was still a conceptual model, which needed to be translated into a formal one by defining the concepts through axioms that restrict the possible interpretations of their meaning, e.g., defining which competences a role has or which sensor observations are valid. A lot of these restrictions were derived from the mind maps and document workflows obtained during the observations or the iterative discussions to construct the innovation binder. However, there were still some formal gaps in the ontology. The goal of this workshop is to capture these decision processes, which can then be translated 


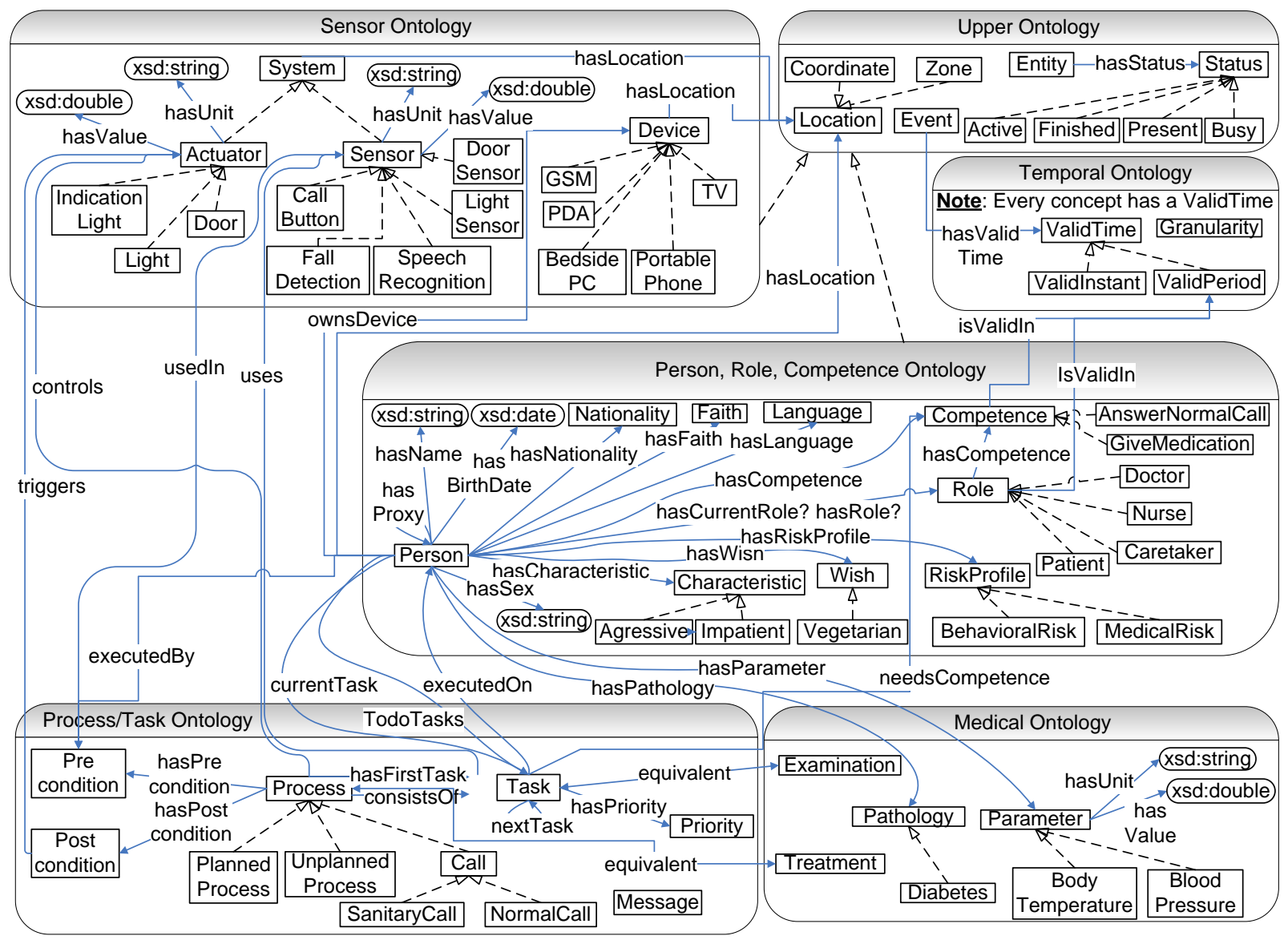

Figure 4. The high-level ontology resulting from workshop 2: scenario role-play

into additional ontology concepts and rules/axioms. For the ontology under development it was unclear how the different care requests were restricted in the priorities and reasons they could get and to which caregivers they should be assigned.

\subsubsection{Participants}

To ensure that the context-dependent factors are captured, a separate workshop was held for the two types of institutional care settings. The workshops took place in the observed settings. The workshop in the care residence welcomed 16 participants, including caregivers as well as managers. The workshop in the hospital was scaled down to four members, i.e., a nurse, head nurse, caregiver and doctor.

\subsubsection{Method}

The workshops took about two hours. Other than the number of participants, the procedure was alike. During the first 10 minutes of the workshop, the participants described a complex situation on paper pertaining to the formal gap we were addressing, e.g., assigning and prioritizing care requests.

Participants were asked to suppose that they were an intelligent system that had a complete overview of the institution, current situation and context. This system is responsible for solving the task pertaining to the formal gap in the ontology. The real life situations described by the participants were selected to further discuss how this intelligent system should ideally handle the task. Each situation started with a very limited initial setup that was illustrated on a blueprint of the working environment of the participants. Different props were used to represent staff, care receivers and material, as shown in Figure 5.

To make a sensible decision, the participants, playing the role of the system, could collect additional information about the situation by asking questions, e.g., how many staff members are present in the department? What are their roles? Instead of immediately giving an answer, a discussion was first held about the importance of the requested information by asking three questions: (1) Why do you feel the 


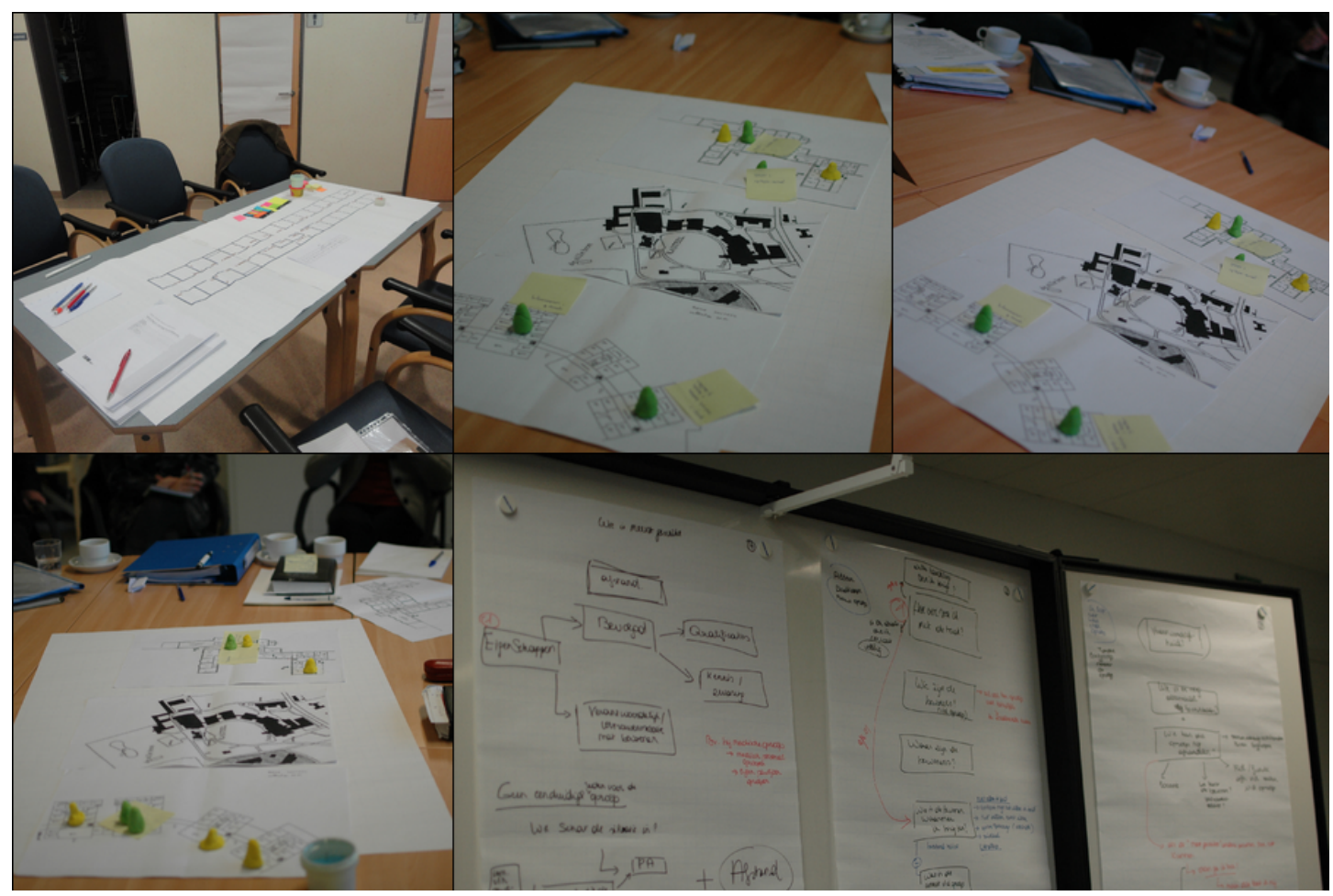

Figure 5. Impressions of workshop 3: scenario is visualized on a layout and high-level concepts, derived from the requested information, are summarized in a decision tree

answer to this question is pertinent? (2) Does everyone agree? (3) Can you give examples of answers to this question? In this way, the researchers could tap into the reasoning made by the participants and minimize their own influence on the process. Finally, the question was answered and visualized by adding or displacing the relevant props on the blueprint. A next question further unravels the situation.

The questions and the order in which they were asked, gave the researchers insights into the needed information and its importance for making a decision. The ontology engineer processed the outcome on paper in the form of a decision tree, as shown in Figure 5. The order of the information in the tree reflects its importance, while the nodes represent high-level concepts to which the questions pertained, i.e., location or task priority, as well as the relations or inter-dependencies that exist between them.

\subsubsection{Analysis \& results}

After the workshop, the decision trees were transformed to more formal ones for each setting. As an example, Figure 6 shows a part of the common decision tree that finds the most appropriate staff members to handle a care request. Bold words refer to concepts from the high-level ontology. The decision trees of both workshops were compared to extract common parts, which were translated to concepts, axioms and rules in the high-level ontology. The other branches are encoded in the low-level ontologies. The workshops also resulted in a new iteration of the innovation binder.

\subsubsection{Reflections}

After conducting the first decision-making workshop in the care residence, it became clear that the participant group should be kept small. Besides the fact that some participants tended to dominate the discussion, we noticed that the large group and presence of managerial functions prevented the actual work processes being uncovered. Participants were inclined to give desired answers that corresponded with institutional or legal procedures, even if, for different reasons, these procedures could not always be followed. However, for our system and underlying ontology to be usable, it is imperative that it is mapped onto the actual work processes, even if they digress from official procedures. Additionally, the larger group made it more difficult for the participants to follow the proposed workshop format and act as one system that needs to re- 


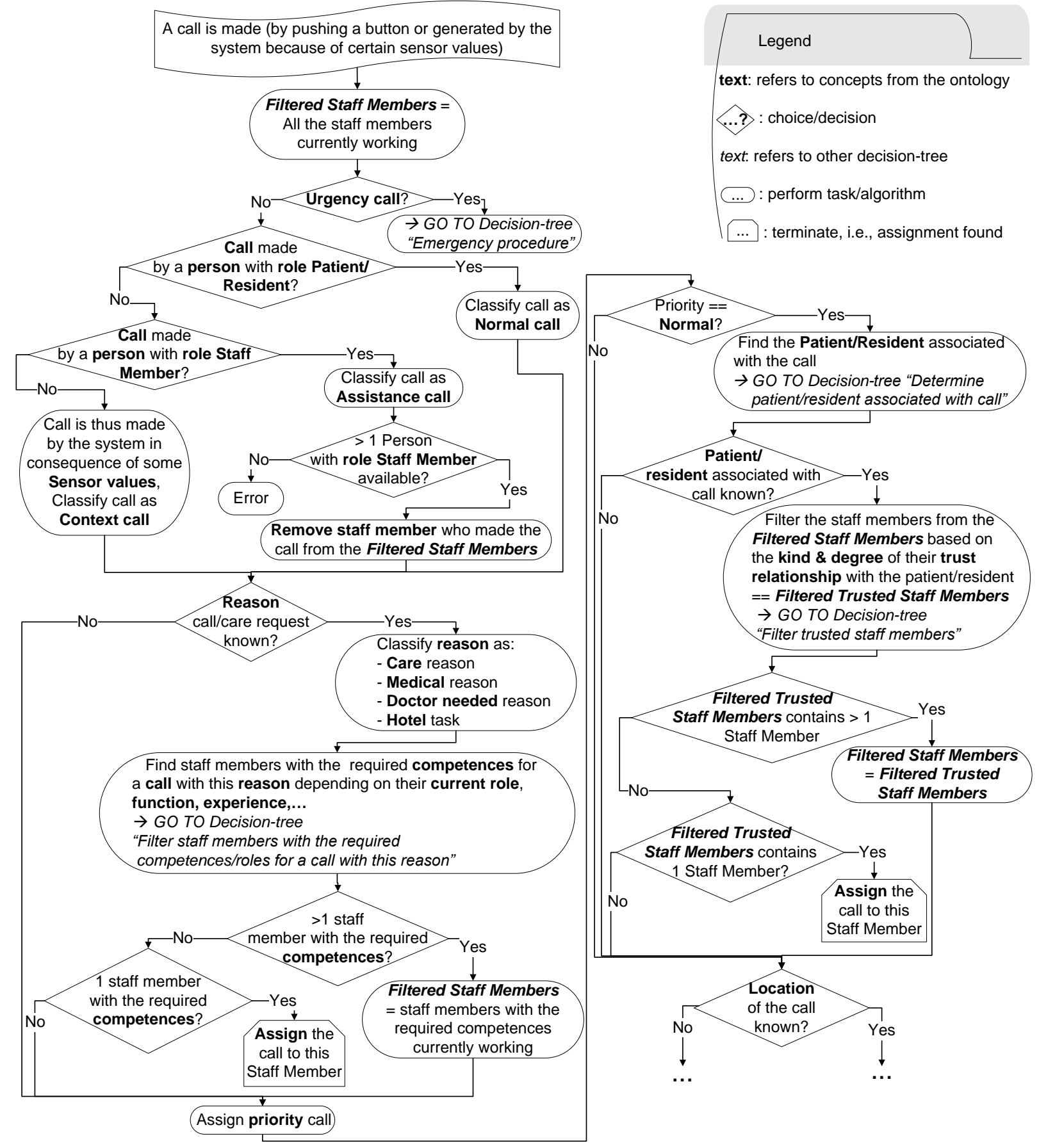

Figure 6. Decision tree to find the appropriate staff member to handle a call or care request

solve the visualized situation on the blueprint. At the second workshop, this problem was further resolved by printing out a larger blueprint so that the participants felt as equal players during a board game.

A lot of concepts on which decisions were based could be derived. For most of these, consensus was reached as to whether they were important to take into account. Prioritization turned out more difficult, as this was situation dependent and it was hard to derive what about the situation influenced it. 


\subsection{Workshop type 4: Concept evaluation}

\subsubsection{Objective}

Based on the achieved decision trees and conceptual ontology model, the prototype of a dynamic nurse call system was conceptualized to demonstrate and evaluate the applicability and completeness of the ontology and accompanying axioms. The purpose of this workshop was a concept evaluation of the prototype under development and to ensure cross-institutional validity of the ontology and reasoning.

\subsubsection{Participants}

To facilitate cross-institutional reflection, 14 participants were recruited with various backgrounds, e.g., nurses, doctors, designers and domain experts, and coming from all types of institutions. Some staff from the observed settings also participated. 4 researchers were involved in the practical organization.

\subsubsection{Method}

The participants were shown an instructional movie of 'slices' of the full scenario that described the conceptual prototype. The selection included new functionality that the research team had introduced, based on the insights gathered during the first three workshops. The researchers chose to make a 'silent' movie in PRoF where the depicted action was explained by intertitles to avoid that the lay actors would struggle with the dialogue. It took half a day to film and a full day to edit.

In the 2.5 hour workshop, the movie was first played entirely, and then repeated and paused every time a new functionality was introduced. This functionality became the subject of a group discussion. For each discussion, the group was split up into smaller groups, guided by two moderators. Remarks and insights were noted down on posters. When the groups reunited, the moderators presented the posters. Additional remarks or insights were added to the posters. The whole workshop was filmed.

\subsubsection{Analysis}

Afterwards, the involved researchers had a discussion, listing the issues that they had observed during the workshop. Later, the entire research team looked at the recordings separately and wrote down their observations and thoughts. These were then discussed in a meeting.

\subsubsection{Results}

The workshop resulted in small alterations to the prototype's algorithm. The decision trees and the accompanying rules and axioms were updated. Adjustments to the prototype were also made.

\subsubsection{Reflections}

The general impression was that visualizing the scenario as a movie stimulated the discussion considerably. The researchers had however somewhat underestimated the novelty of the prototype, especially because the participants had such different profiles. Even though some background on the project was given at the start of the workshop, some participants had difficulty grasping the full range of the project. More information about the project, the field research, the preceding workshops, and insights the new system was based on, should have been given. While the movie introduced all the functionality gradually, it still felt like too much new information was given at once.

The workshop resulted in considerable feedback for the algorithm of the nurse call system and thus the axioms \& rules captured in the ontology. However, no changes were made to the concepts and relations of the ontology. This could mean that the method was less suited for ontology feedback, but it can rather be understood as a confirmation of the ontology. Although the workshop was certainly focused on the nurse call system, missing concepts in the ontology or false relations should have come up during the discussions. Therefore we are inclined to see the lack of input for the ontology as a confirmation of the ontology, rather than concluding the method was unsuited for cross-institutional ontology evaluation.

\subsection{Workshop type 5: Embodied system use}

\subsubsection{Objective}

After workshop 4, the conceptual graphs and decision trees were translated into an ontology language. As the goal was not to overburden the stakeholders, they were not actively involved in this implementation 
phase. However, to prevent losing sight of the user requirements when making implementation decisions, the ontology engineers constantly validated the ontology with the scenario in the innovation binder.

The Protégé editor (Knublauch et al., 2004) was used to develop the continuous care ontology in OWL. Hermit Reasoner (Motik et al., 2009) was used to check its consistency and classification. The Semantic Web Rule Language (SWRL) (Horrocks et al., 2004) was used to express rules. The resulting continuous care ontology is discussed in Section 3. Based on this ontology, the prototype of the dynamic nurse call or care request system was implemented as described in Ongenae et al. (2012).

This workshop aimed to give the participants a first-hand experience of the prototype in order to generate deeper reflection on both the application and the ontology on which the application was built.

\subsubsection{Participants}

All 15 participants worked in a care residence or a hospital (not necessarily the observed ones), or did so until recently, for instance, teachers at a nursing school. They all had first-hand experiences with some sort of care request system.

\subsubsection{Method}

The implemented prototype together with its senors, e.g., RF tags for localization or temperature sensors, and devices, e.g., smartphones running the novel nurse call assignment application or the light control system, was integrated in PRoF, as shown in Figure 7. This prototype allowed users to experience a fully immersed, more profound, contextual experience of the system in a lifelike context. As we wanted the participants to have a complete experience of the system, we invited small groups, i.e., two or three users, so that they would be occupied at all times and the researchers could follow them one-on-one. As such, seven workshops were organized for 15 participants. All workshops were filmed.

The 2.5 hour workshop started with an elaborate introduction, consisting of two movies framing the project and informing the users of the functionality of the prototype. Two researchers then interviewed them on their experiences with care request systems and the experienced limitations. Next, the participants were given a thorough introduction of the various devices, especially the smartphone applications. The test users than played out seven scenes in the PRoF. For each scene, they received a persona and context card. After scene two and five, the functionality of the system was discussed shortly. After all the scenes, a more elaborate discussion was held.

\subsubsection{Analysis}

During the workshops, the researchers immediately noted down the first emerging insights. These were gathered in a draft document. These workshops resulted in a considerable amount of video data, which was split among the researchers. They went through their part of the data on their own and wrote down their insights. These were then clustered and analyzed.

\subsubsection{Results}

Just as in workshop 4, this workshop resulted in more feedback for the application than it did for the ontology. For instance, some missing functionality was noted or minor remarks regarding the user interface were made. It did give the engineers insights into the pitfalls, difficulties and doubts that have to be taken into account when introducing this ontology-based application in the working environment.

\subsubsection{Reflections}

After workshop 4, the researchers realized a more elaborate introduction to the ontology and its application was needed. Therefore, on average 30 minutes were reserved for introduction. This seemed to improve the participants' understanding of the system, but during the scenes, additional explanations were sometimes still needed. In fact, the role-play increased the participants' understanding of the system most, and it was only after playing a few scenes that some participants fully grasped the system's operation. Similarly, while most participants expressed to be impressed after a first glance at the system, a more thorough experience of the system made them more critical.

The researchers were pleasantly surprised by the easy uptake of the role-playing exercise by the participants. Even the rather reserved participants, got more engaged in the exercise after playing out a few 


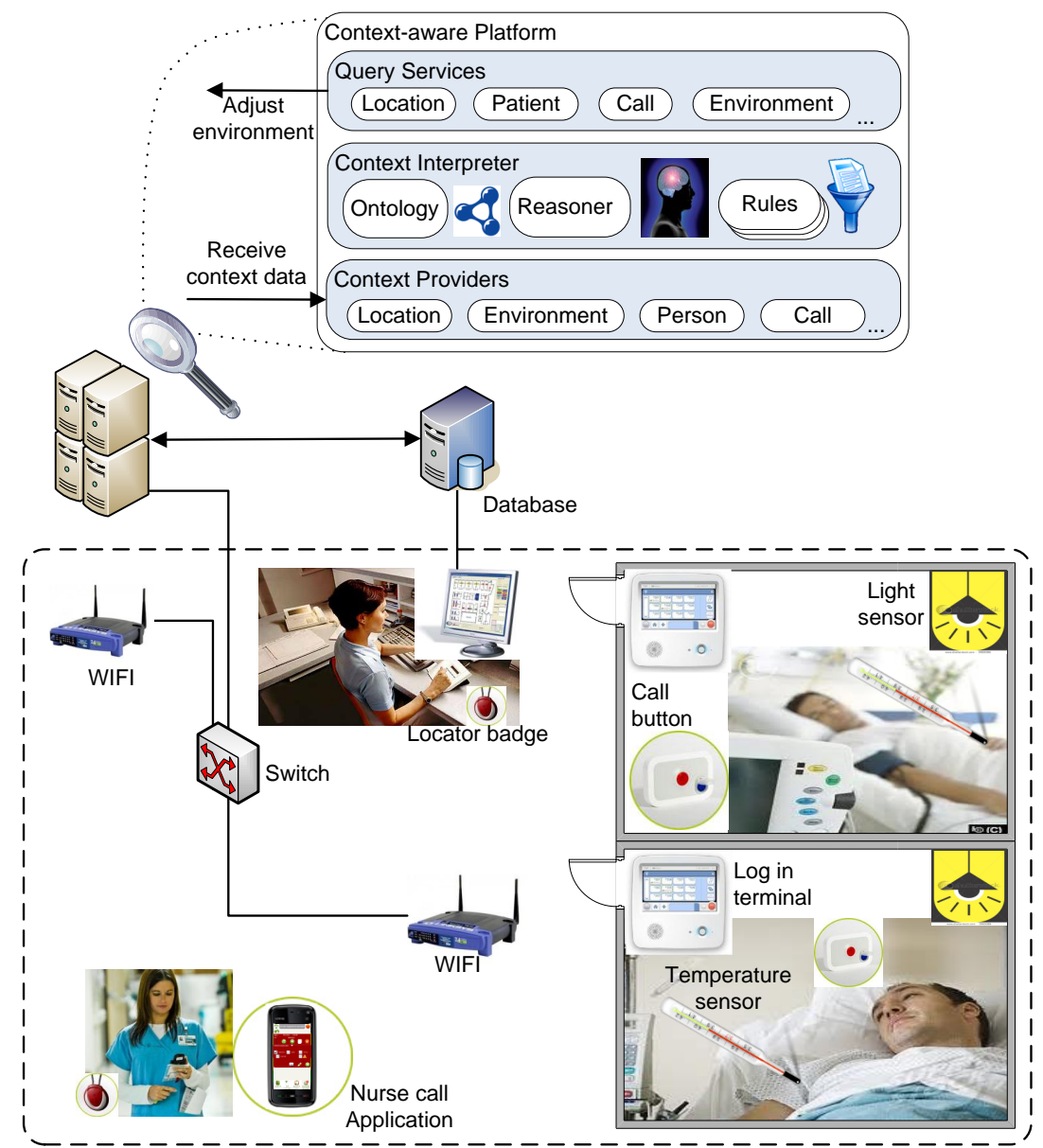

Figure 7. The setup of the nurse call prototype in PRoF for workshop 5: Embodied system use

scenes. Therefore, we feel that these workshops were a success, despite a high investment of time of all researchers involved. The workshop gave the researchers much feedback on the algorithm of the prototype and only minor feedback on the concepts/relations in the ontology. Again, this could be due to the fact that the ontology already contained most concepts and relations in the cure and care field, or due to the fact that the method was not suited for ontology validation.

This is not to say that the described user involvement could not be improved. Although the final tests took place in PRoF, which was very close to reality, it was felt that a real-life setting could generate further insights. It will be investigated how a mobile set-up of the system can easily be tested in a real-life work setting. However, the varying available technology and networks make this a challenging endeavor. During the final tests, some technical issues popped up, which threatened to reduce the user tests to technical tests. This was to be expected, as the implemented application is merely a prototype. Although these issues were quickly solved, it was sometimes hard to distinguish the participants' feedback on the system from feedback related to technical system failure.

\section{The co-created continuous care ontology}

\subsection{The high-level continuous care ontology}

The six sub-domains of the high-level ontology defined during the role-play workshop, see Section 2.4, were mostly retained. However, the sub-domain pertaining to person profiles and roles \& competences was split up in two. Moreover, the general sub-domain was divided into the context and upper ontolo- 


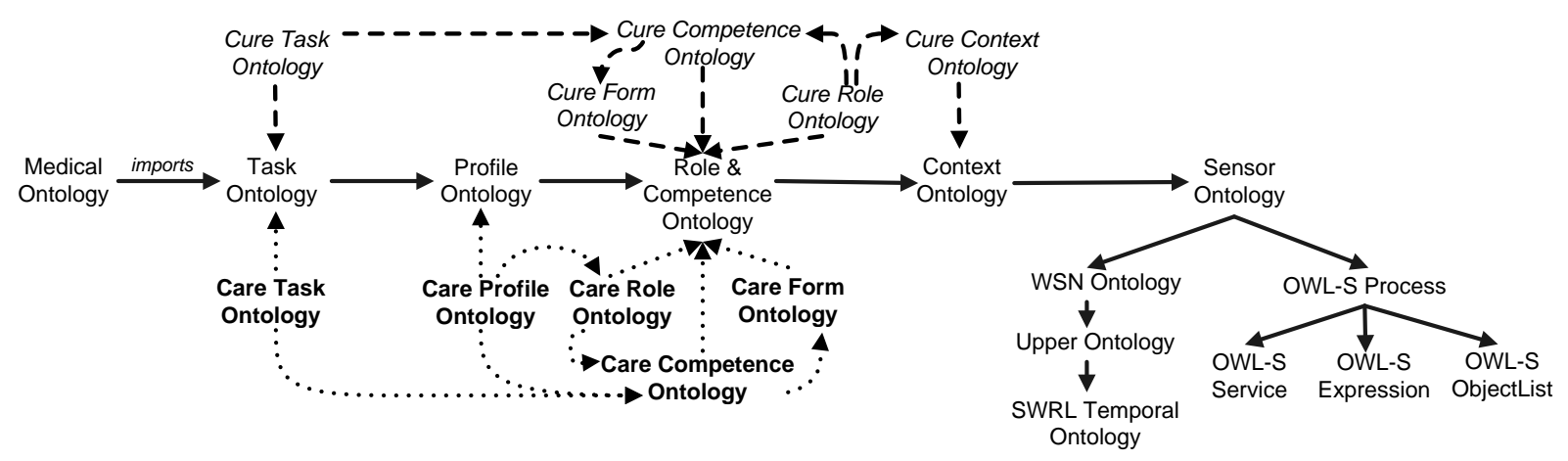

Figure 8. Import schema of the high-level continuous care ontology and the low-level care (bold \& dotted arrows) and cure (bold \& dashed arrows) ontology

gies. The latter subsumes the temporal sub-domain. The import schema of all the ontologies that make up the high-level ontology is visualized in Figure 8. The properties of the seven parts of this ontology are summarized in Table 1. It shows the number of datatype and object properties, classes and axioms that are defined in each part of the ontology. It also indicates the amount of time needed to check the consistency and classify each ontology. Note that the reasoning times for a particular part of the ontology, also include reasoning over all the other ontology parts that are imported by this part. The reasoning times were gathered by running Hermit Reasoner 1.3.8 on a machine with the following specifications: Intel(R) Xeon Central Processing Unit (CPU) E5645 2.40 gigahertz (GHz) with 2 gigabyte (GB) Random-Access Memory (RAM) running Windows 7 Enterprise 64-bit. The seven parts of the high-level ontology are presented in detail in the following subsections.

\subsubsection{The upper high-level ontology}

A lot of concepts defined in existing top-level ontologies (Mascardi et al., 2006) clashed with concepts defined in the ontologies we wanted to import. The SWRLTemporalOntology (O'Connor and Das, 2010) was imported to model complex interval-based temporal information, e.g., tasks that need to be performed before a certain point in time or for logging purposes.

The upper high-level ontology, of which the most important concepts are shown in Figure 9 preceded by the upper namespace, describes general classes, relations and axioms. Most importantly it enables that data can be related with an unique ID. It also extends the SWRLTemporalOntology, of which the concepts are preceded with the temporal namespace in Figure 9, with additional concepts modeling the current temporal context, e.g., the current shift or holidays. All the other high-level ontologies import the upper high-level ontology and define all their concepts as subtypes of the ExtendedProposition concept.

\subsubsection{The sensor high-level ontology}

As the ambient intelligent care room of the future will contain numerous sensors and actuators to support caregivers and care receivers in their activities, it is important to model the information delivered by these devices in the ontology. A comprehensive list of existing ontologies to describe sensors and sensor networks can be found in the W3C Semantic Sensor Network XG Final Report (Barnaghi et al., 2011). Within

Table 1

The properties of the 7 ontologies that make up the high-level continuous care ontology

\begin{tabular}{|c|c|c|c|c|c|c|c|}
\hline Ontology & $\begin{array}{c}\text { Nr. of } \\
\text { classes }\end{array}$ & $\begin{array}{c}\text { Nr. of object } \\
\text { properties }\end{array}$ & $\begin{array}{c}\text { Nr. of datatype } \\
\text { properties }\end{array}$ & $\begin{array}{c}\text { Nr. of } \\
\text { axioms }\end{array}$ & $\begin{array}{c}\text { OWL } \\
\text { profile }\end{array}$ & $\begin{array}{c}\text { Reasoning time } \\
\text { consistency check (ms) }\end{array}$ & $\begin{array}{c}\text { Reasoning time } \\
\text { classification (ms) }\end{array}$ \\
\hline Upper & 14 & 10 & 7 & 163 & ALCHOQ(D) & 47.33 & 77.07 \\
\hline Sensor & 156 & 69 & 20 & 980 & ALCHOIQ(D) & 62.43 & 145.23 \\
\hline Context & 47 & 13 & 8 & 277 & ALCHOIQ(D) & 29.10 & 164.53 \\
\hline Role \& Competence & 33 & 19 & 2 & 212 & SHOIQ(D) & 40.00 & 200.47 \\
\hline Profile & 36 & 42 & 4 & 319 & SHOIQ(D) & 44.23 & 386.13 \\
\hline Task & 41 & 28 & 9 & 375 & SHOIQ(D) & 42.73 & 542.23 \\
\hline Medical & 33 & 27 & 1 & 266 & SHOIQ(D) & 51.07 & 572.40 \\
\hline \hline Complete high-level & 360 & 208 & 51 & 2592 & SHOIQ(D) & 51.07 & 572.40 \\
\hline
\end{tabular}




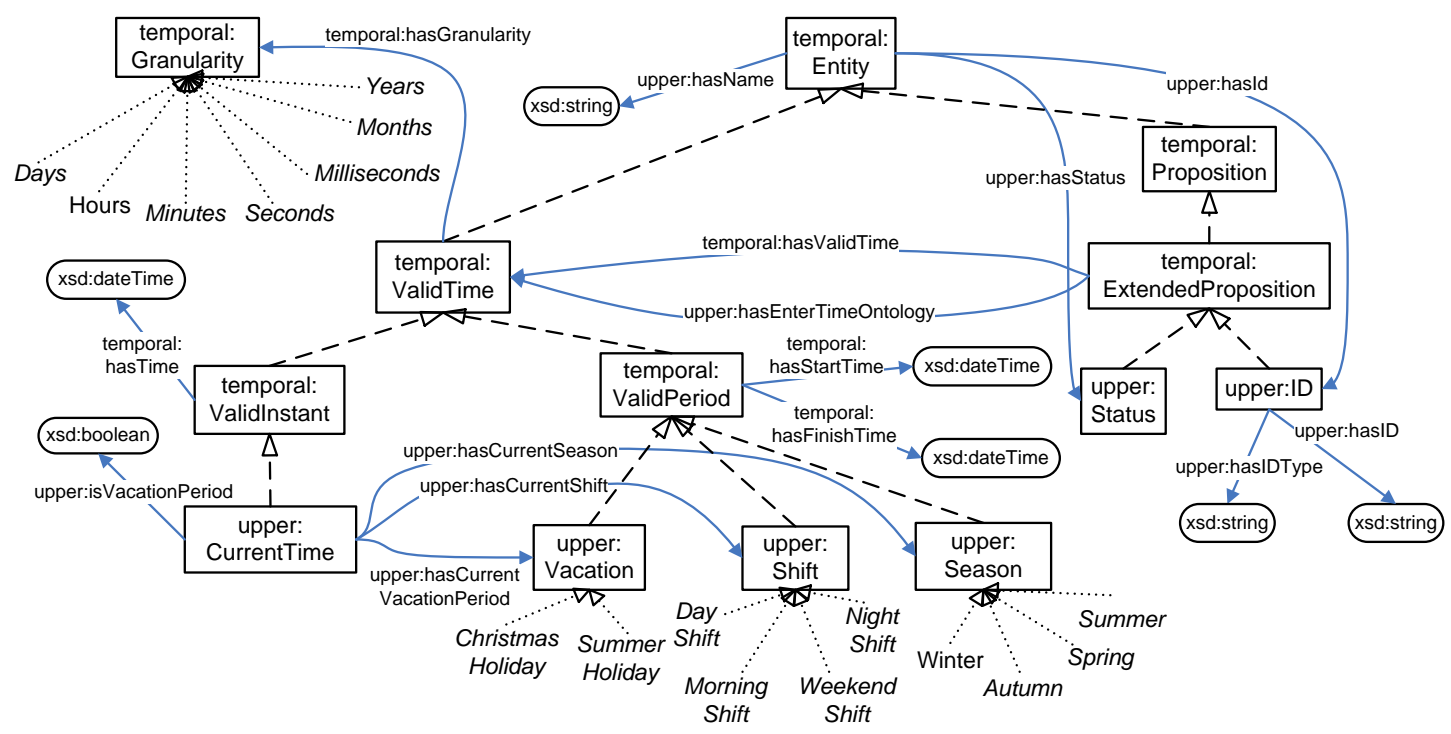

Figure 9. Prevalent concepts of the upper high-level ontology

the iMinds DEUS Project (2010) the Wireless Sensor Network (WSN) (Verstichel et al., 2010) ontology was developed. The most important concepts of this ontology are visualized in Figure 10, preceded with the wsn namespace. The model contains a System concept, which models a system and its components. The ontology allows interpreting and attaching meaning to the data values monitored by the sensors by modeling them as Observations. Rules added to the ontology allow detecting specific phenomena, called Symptoms, in these observations, e.g., the humidity is zero. Classification axioms allow reclassifying these symptoms as Faults, e.g. the humidity in the room is too low. Each fault can then again be reclassified as a Solution, e.g., turn on the humidifier in the room.

The sensor high-level ontology extends this WSN ontology with systems, sensors and actuators and their associated observations, faults and solutions that play an important role in continuous care settings. Some representative examples are shown in Figure 10 preceded by the sensor namespace.

\subsubsection{The context high-level ontology}

The context high-level ontology models the contextual environment information. The prevalent classes of this ontology are preceded by the context namespace in Figure 10. The most important concept is the ContextGroup, which is a logical grouping of entities, e.g., a care receiver with all his or her devices, sensors, actuators, room, bed, equipment and items. The concept is defined through rules, as the composition of a context group constantly changes based on information in the ontology, e.g., the location or status of people. This ontology also contains all the information related to localization. A Location can be a Coordinate or a Zone, e.g., rooms or departments. The first is fully defined by its $\mathrm{x}$ - and $\mathrm{y}$-coordinates, while the latter is defined by its centre coordinate and a radius. The context high-level ontology also introduces a subtype of System, namely a Device. A device is a logical grouping of sensors and actuators. It is associated with a status, e.g., on or off. Devices and zones can be associated with their Function or purpose.

\subsubsection{The profile high-level ontology}

The profile high-level ontology, of which the most important concepts are preceded by the profile namespace in Figure 11, models the profile information about staff members and care receivers that was indicated by the stakeholders as important to take into account when optimizing continuous care processes. This model associates each Person with a Profile, which consists of a Basic and a Risk Profile. The first models the important administrative, e.g., birth date, biological, e.g., sex, psychological, e.g., aggressive, and sociological information, e.g., nationality, about a person. This information needs to be inputted into the system or extracted from documents, e.g., the medical file of a care receiver. In contrast, 


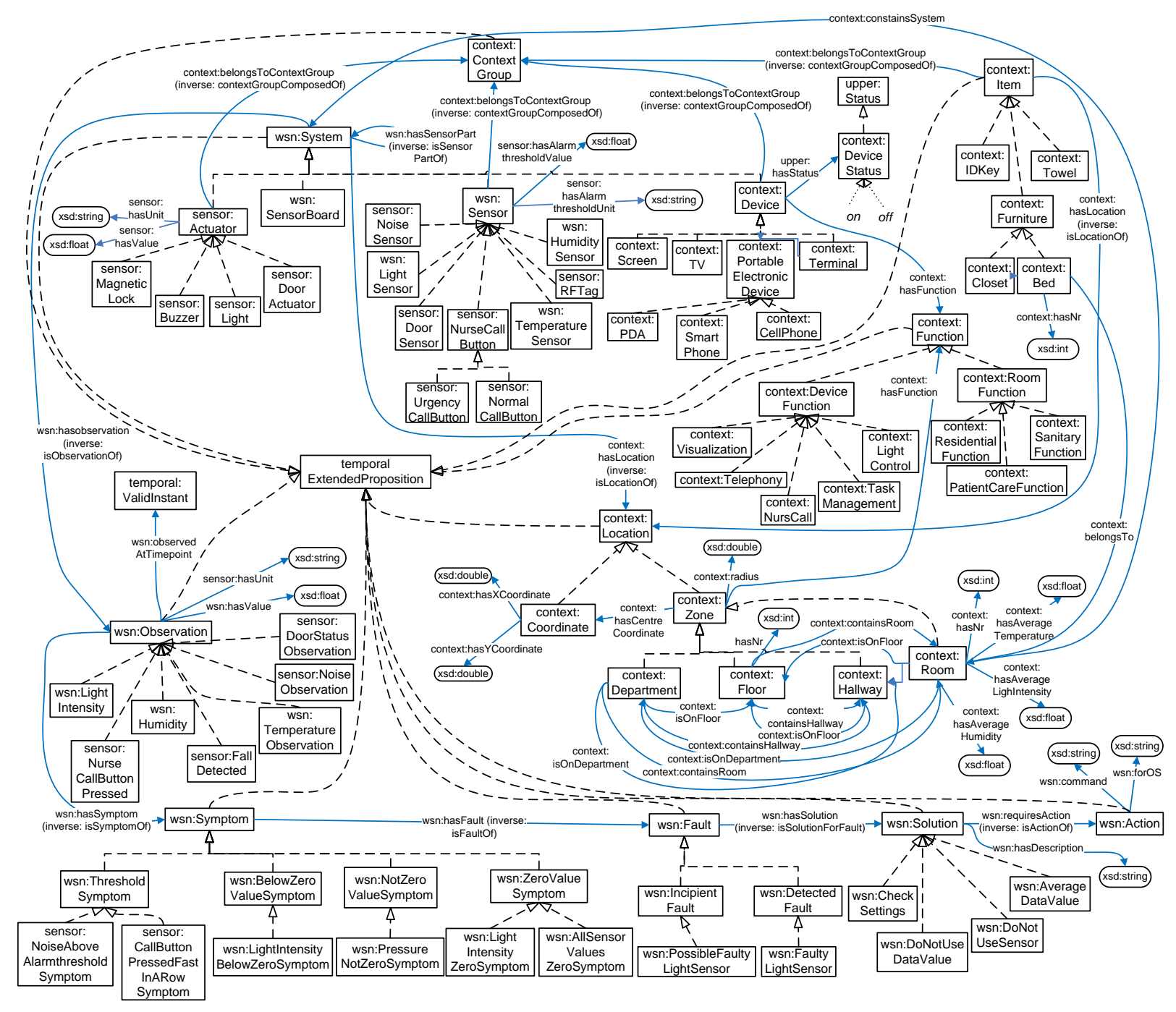

Figure 10. Most important concepts of the sensor \& context high-level ontologies

the risk profile is defined by classification axioms and rules. This allows a reasoner to automatically obtain the risk profile of a person by reasoning on the information in the basic profile.

The profile high-level ontology models the Trust Relationship between people. Three types are differentiated, i.e., Family, Personal and Therapeut ic Relationship. The first indicates that people are related. The second represents some kind of personal bond, i.e., friendship. The third models a trust relationship that has been established between two people in the context of a person's care/health. Each trust relationship can be associated with a degree that expresses its strength. This allows that the trust relationship is taken into account according to different degrees of specificity by various applications. It might be enough that there exists a trust relationship between two people, e.g., a physician can access the medical file of a patient because there exists a therapeutic relationship, but sometimes the degree of this relationship might also be important, e.g., in a care residence a care receiver has a personal assistant with whom they might have a personal bond of high degree, next to the therapeutic relationship.

Finally, this ontology associates the Person concept with a lot of classes from the already discussed ontologies to indicate, e.g., the location of the person or which items and devices he/she owns. A person can also have a status, e.g., free or busy. 


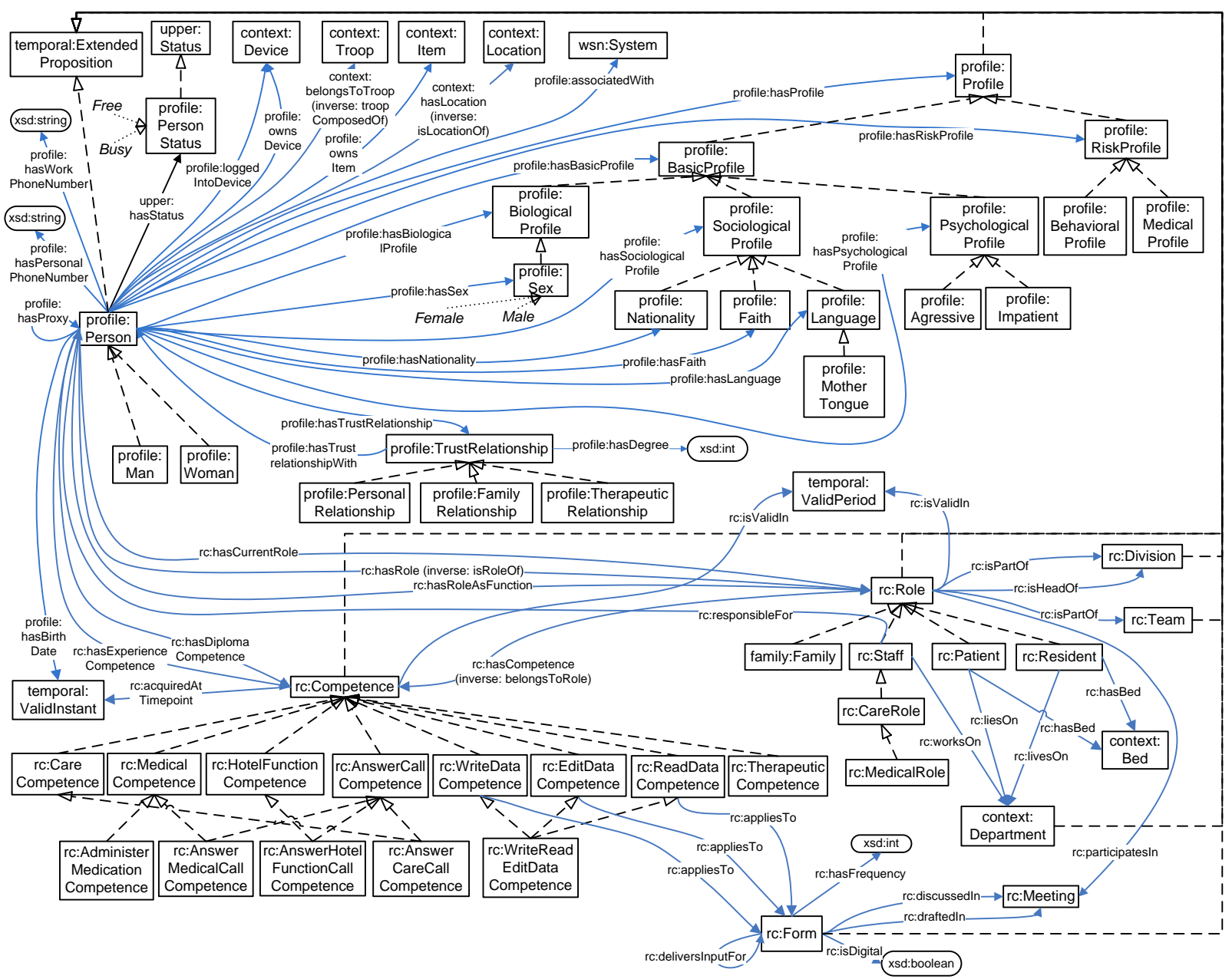

Figure 11. Most important concepts of the profile and role \& competence high-level ontologies

\subsubsection{The role \& competence high-level ontology}

Research on representing roles in knowledge representation models (Fan et al., 2001; Sunagawa et al., 2004; Steimann, 2007; Bachman and Daya, 1977) has shown that it is preferable to model Entities, i.e., things that are, Events, i.e., things that happen, and Roles, i.e., things that are, but only in the context of things that happen, as separate concepts with separate hierarchies. This way roles can be easily destroyed, created and transferred between entities and properties can be added. As shown in Figure 11 preceded by the $r c$ namespace, the role \& competence high-level ontology adopts this approach by modeling Persons and Roles separately. A role instance is associated with an entity instance and it does not exist independent of that entity. Properties were modeled for the different roles, e.g., the department a person works on when he/she has a specific role.

Our model extends further on this representation by defining each role by its Competences through classification axioms, e.g., a Doct or is defined as a role that has all the medical competences. This allows writing algorithms that find appropriate staff members to fulfill tasks based on the required competences.

Each person is associated with competences and roles through five relationships:

- hasfunction: primary role of this person, i.e., the role for which this person was primarily hired.

- hasRole: models all the roles this person can have.

- hasCurrentRole: role the person is currently fulfilling within the care setting.

- hasDiplomaCompetence: extra competences this person has acquired by following courses.

- hasExperienceCompetence: extra competences this person has acquired through experience. 
Little previous work was found on modeling specific roles and competences that occur within the continuous care domain. However, The Family SWRL Ontology (2013) was reused to model the family relationships of the care receivers. These reused concepts are preceded by the family namespace in Figure 11.

\subsubsection{The task high-level ontology}

A wide range of ontologies exist to model process workflows (Gangemi et al., 2005; The Process Ontology, 2013; The SUPER Ontologies, 2013; PSL, 2013; BMO, 2013). However, most of these are focused on business process management, are not expressed in OWL, contain a lot of concepts and/or are limited in the ability to construct process workflows automatically from a set of specified tasks. OWL-S (Martin et al., 2004), which is an ontology for describing Semantic Web Services, also contains a process model as visualized in Figure 12 preceded by the owls namespace. An OWL-S Process can generate and return some new information and produces a change in the environment based on the information it is given and the context. This is described by the has Input, hasOutput, hasPrecondition and hasEffect relations. For a process to be able to execute, all its preconditions need to be fulfilled. The Result of the process is the combination of its output and its effect. This allows automatically mapping the effects and outputs of one task on the inputs and conditions of another one. By using the CompositeProcess and Controlconstruct concepts, workflows can be constructed that start from particular input and context and reach a specified effect and result by combining various processes.

The task high-level ontology extends this OWL-S Process ontology, as shown in Figure 12 preceded by the task namespace. It is modeled that the precondition of a process can depend on the value of a sensor and that the effect can be the status change of an actuator through the usedIn and controls relations. The Task concept is introduced to model the various continuous care tasks. It is equal to a Process, but is further divided into planned and unplanned tasks. Each task has also an associated Status, e.g., Assigned or Finished, and Priority. From the observations and workshops it was clear that the stakeholders preferred three levels of priority, namely very urgent, urgent and normal. Each task is defined by the Competences which are needed to execute it. The location at which this task is preferably executed can also be indicated.

Consider, for example, the task of assigning a person to a call or care request. A Call is modeled as an unplanned task. For each type of call it can then be specified which competences are needed to handle it, e.g., Medical Calls can only be handled by a person who has medical competences, and its preconditions, e.g., a care receiver pushes a call button, its input, e.g., the location of the button, its output, i.e., the assigned staff, and its effects, e.g., the assigned caregiver's smartphone rings, are modeled by using concepts from the OWL-S Process ontology.

\subsubsection{The medical high-level ontology}

As mentioned in Section 1.2, a wide range of ontologies exist about the eHealth domain. We are mainly interested in medical knowledge that influences the way care is organized, e.g., diabetes (influence on food consumption) or muscle paralysis (higher need for care). The Galen Common Reference Model is a model of clinical categories plus sufficient information about those categories to allow them to be classified automatically. The model avoids adding too many axioms that constrain the possible interpretations of a concept, unless there is very wide agreement about it. Therefore this model can easily be integrated without contradicting with the knowledge already contained in our ontology. The medical high-level ontology extends the Galen Common Reference Model. The concepts of these models are preceded by the med and galen namespace respectively in Figure 12. The added axioms and rules express relations between the imported medical knowledge and additional medical concepts needed for the continuous care domain.

The medical high-level ontology associates each Person with his or her Medical Parameters and indicates how it was measured by the hasMeasurement Type relation, i.e., observed by caregivers, measured by monitoring equipment, derived from other parameters or derived from a sample in a laboratory. Each parameter can be associated with a sample. Finally, a Person is associated with his or her Prescriptions and Diagnosis. The first is defined by the prescribed PharmaDrug and Dose. 


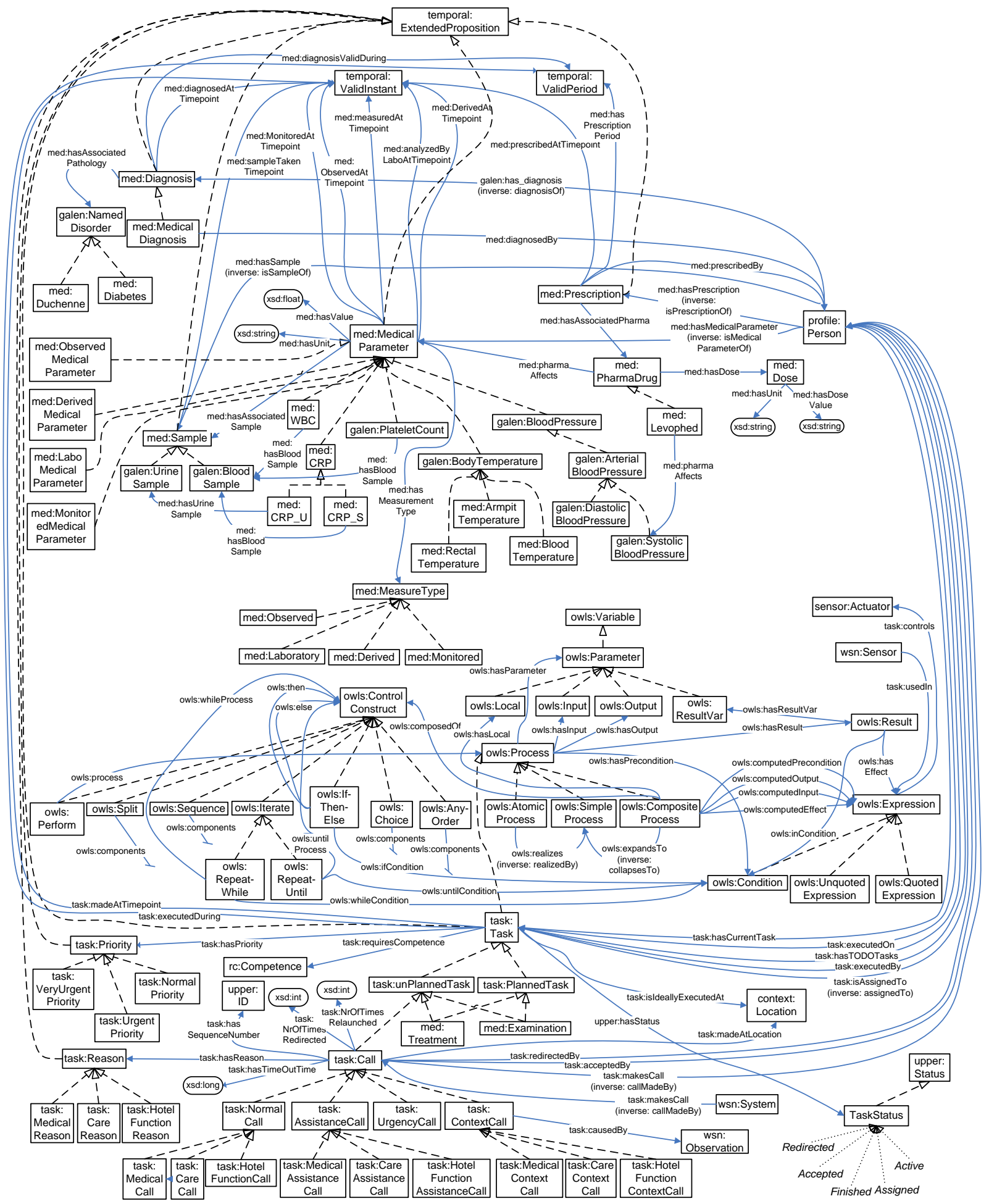

Figure 12. Prevalent concepts of the task \& medical high-level ontologies

\subsection{The low-level ontologies}

The low-level care and cure ontologies consists of five and four sub-domains respectively, namely:

- roles for the care \& cure domain,

- competences for the care \& cure domain, 
- forms used within the care \& cure domain,

- care \& cure tasks,

- profile information specific for the care domain, and

- context location information specific for the cure domain.

The import schema of these ontologies and how they relate to the high-level ontology is visualized in Figure 8. Some example concepts are shown in Figures 13 and 14, preceded by the care and cure namespaces respectively. The low-level ontologies are derived from the mind maps and document flows and the results from the decision-making workshops. Additionally, the medical competences were derived from an official document, namely 'Inventory of Nursing Acts', which details all the competences that nurses can execute according to their diploma as stipulated by the Belgian Government. The low-level cure \& care ontologies contain some concepts with the same name that were not included in the high-level ontology as they are not used with the same meaning within the two settings, e.g., documents with a different purpose and roles that map on different competences.

The low-level cure context ontology extends the high-level context ontology with subclasses that model typical departments, e.g., Radiology, rooms, e.g., Nurse Post, and hallways, e.g., Stroke Unit, within hospitals. This ontology was only constructed for the cure domain as hospitals typically have a very common structure, which is similar across multiple sites.

The low-level care \& cure document ontologies extend the Form and Meeting classes of the highlevel role \& competence ontology with specific used document formats and regularly organized meetings.

The low-level care \& cure competence ontologies extend the Competence class of the high-level role \& competence ontology with specific competences which are needed to execute all the tasks and daily activities within the two settings and how they are related to each other. Six types can be discerned, namely Medical Competences pertaining to curing the care receiver and are usually fulfilled by staff with a medical diploma, Care Competences, e.g., Washing or Dressing a Patient, Hotel Function Competences, e.g., changing or making the bed, Therapeutic Competences modeling competences needed to draft and follow-up a specific therapy, grouped according to therapeutic branch, e.g., Logopaedic, Logistic Competence, e.g., preparing meals or transporting care receivers, Financial Competences pertaining to managing the finances of the residential care setting or specific residents and finally competences related to reading, writing and adapting document captures by the Edit, Read and Write Data Competences. The latter are connected through the applies To relation with the specific document they pertain to.

The low-level cure \& care role ontologies extend the Role, Team and Division classes of the high-level role \& competence ontology. A distinction is made between Staff Members, Residents or Patients and Family. In the care settings, Volunteers and the Responsible of the User Council are also modeled. Further subclasses of Resident can be defined based on the specific illnesses treated at the care setting, e.g., Not-Congenital Disorder Resident, or specific tasks that the resident is allowed to perform, e.g., Job Volunteer. An important subclass of Staff Member is the Care Role class, which is further divided into all the types of roles filled by people caring for a person. In the low-level care ontology, an important distinction is made between Residential Counselors and Nurses who work during the Day, the Night and the Weekend as they do not have the same competences and tasks, e.g., the weekend and night nurses are expected to also perform caring tasks and not only medical tasks. Roles that can be occupied by nurses or residential care settings depending on the institution are modeled as direct subclasses of Care Role. The isButterfly relationship indicates whether a Medical Role or Residential Counselor is a person who is not connected to a specific department, but can work on different departments depending on where staff is needed at the moment. Next to the caring roles a lot of other roles are needed at both the residential care setting and hospital, e.g., Cleaning Team or Social Worker, which are modeled as direct subclasses of the Staff Member class. A final important Staff Member role is the Intern role. Each role can be occupied as an intern. However, the tasks that interns can perform are very different and often more limited. They also often need supervision to perform certain tasks and their competences and responsibilities 


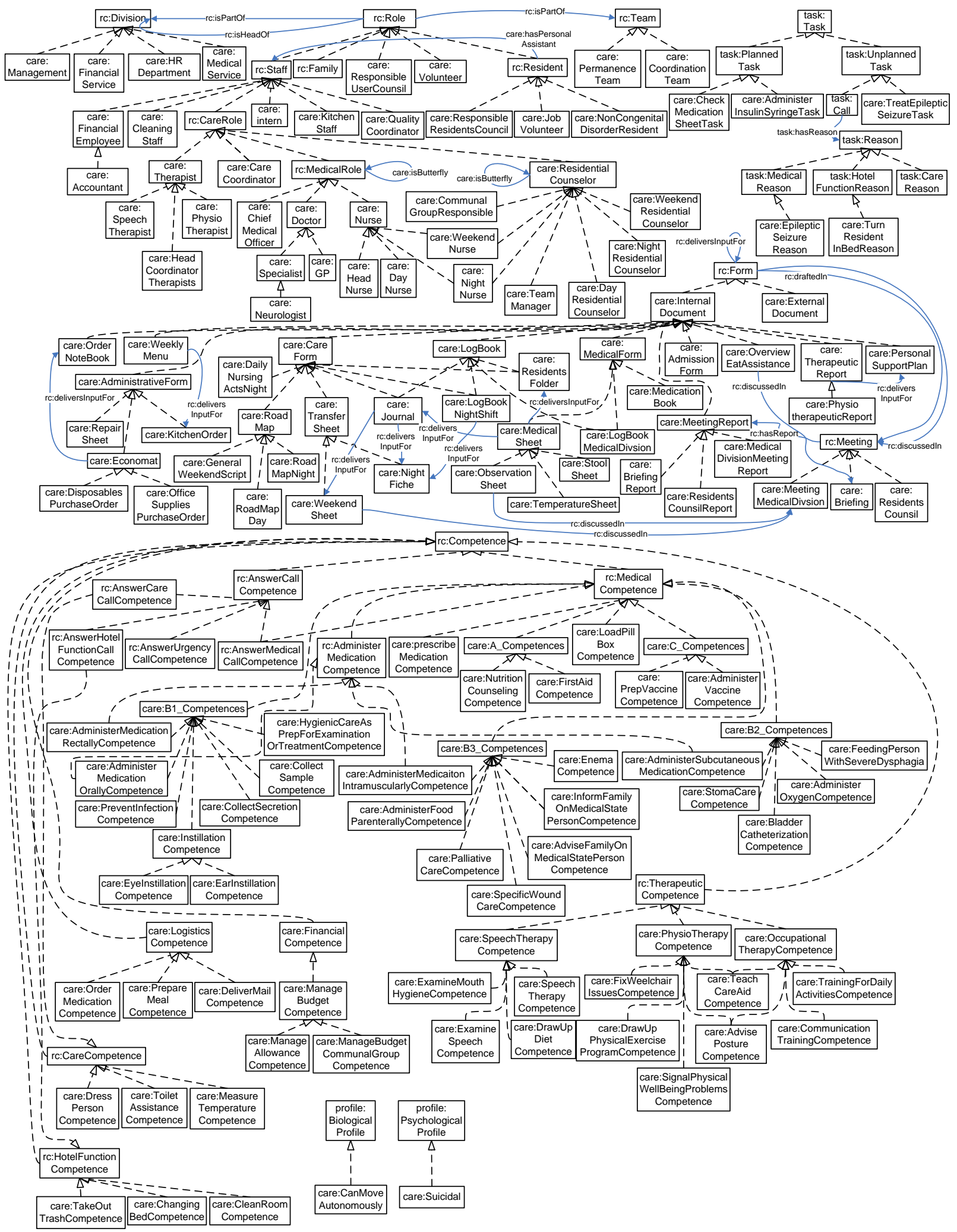

Figure 13. Example concepts of the low-level care ontology

change depending on their experience level. Therefore, a separate class was created for the Intern role and the hasExperienceCompetence and hasDiplomaCompetence relations are used to specify 


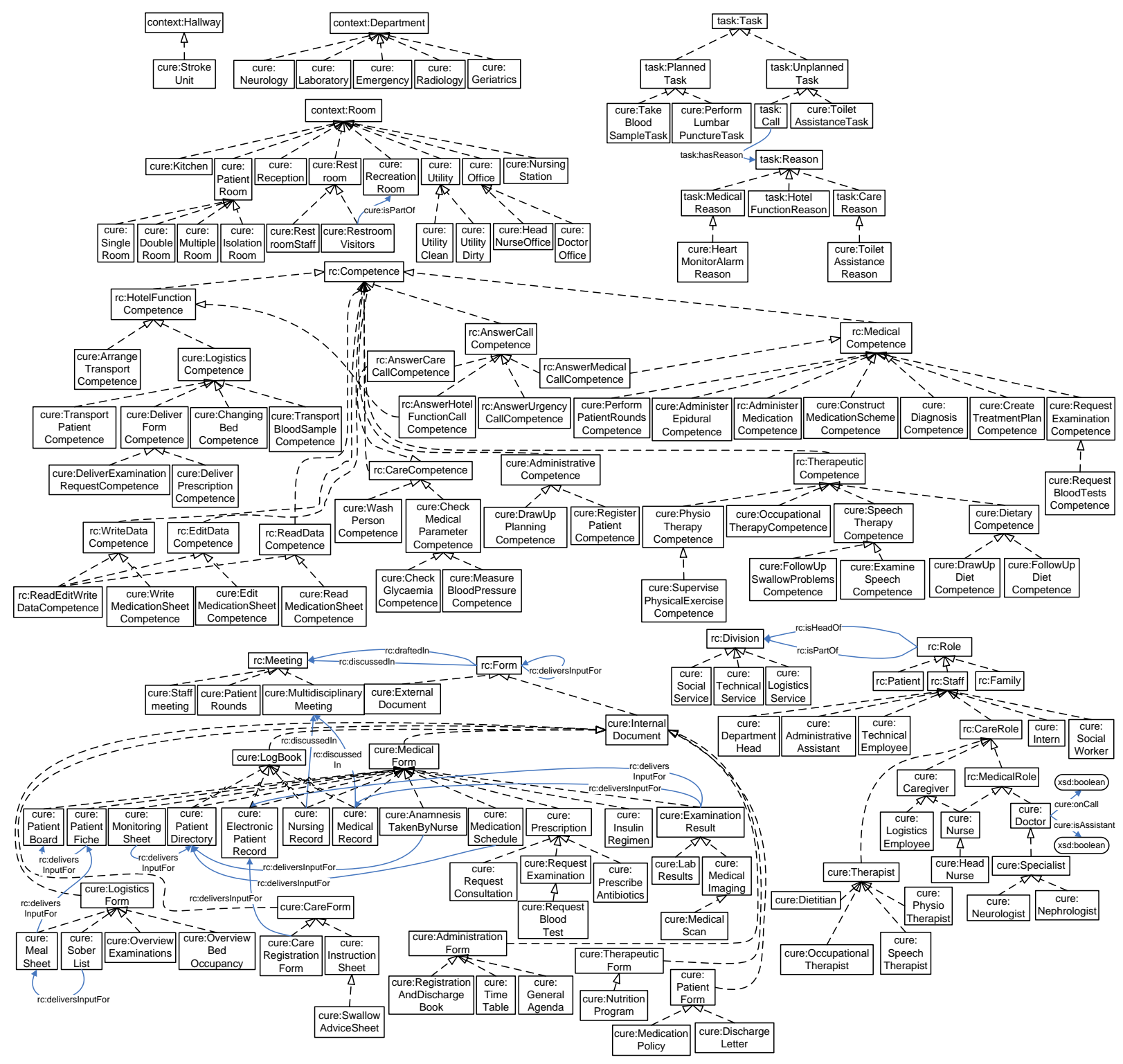

Figure 14. Example concepts of the low-level cure ontology

their competences depending on the specific situation and context. Each care \& cure role is then further defined by mapping it on the appropriate care \& cure competences, which are modeled in the low-level cure \& care competence ontologies.

Additionally, these low-level cure \& care role ontologies define the divisions and teams which are typically present within the care \& cure domain. It is defined which roles are part of a certain team or service and which role is the head of a service or department. For example, each person who has the role Social Worker is automatically part of the Social Service.

The low-level care profile ontology, extends the Profile class of the high-level profile ontology with subclasses that represent common traits which residents display at a residential care setting, e.g., being able to move independently or being suicidal.

The low-level care \& cure task ontologies extend the Task and Reason classes of the high-level task ontology. By using the is InNeedOfCompetence these care tasks can then be mapped on the competences, which are defined in the low-level care \& cure competence ontologies and are needed to perform the task. By using the other relations defined in the high-level task ontology the different care tasks can be related to each other. For example, the task Administer Insulin Syringe can only be performed 
by people who occupy a role that has the competence Administer Intravenous Medication. Moreover, this task is a Composite Process, which is composedof a Sequence, with as components first the Check Medication Sheet task and second the Administer Syringe task. For the first task, the Read Medication Sheet Competence is needed.

\subsection{The rule-based algorithms}

Rule-based algorithms were developed that contain the algorithms to optimize and automate continuous care. They infer new knowledge based on the information available in the ontology. Efficient and fast notifications made by these rules allow appropriate actions to be taken by the staff. E.g., the following rule assigns a staff member with medical competences to an urgent medical request from a care receiver:

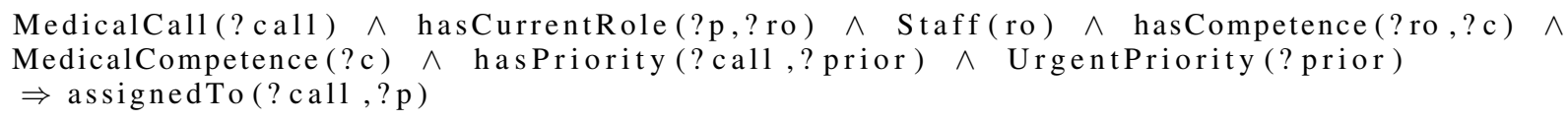

\section{Discussion}

In Table 2 the various workshops are compared. First, the number of participants is considered. We experienced that a large group of participants is beneficial for explorative workshops like workshop 1. In this workshop, a large group of stakeholders were sensitized and got their first experience with ontologies and the project. Many of these participants were also involved in the other workshops. Therefore, this workshop was a good way to create awareness and advocates in the stakeholders group. But, for instance, workshop 2 may have benefited from a smaller group of participants. The issues raised during the discussions varied widely and the researchers struggled to keep focus in the conversation. The same thing can be said about workshops 3a. Workshop $3 \mathrm{~b}$ resulted in more targeted feedback thanks to the smaller group.

Second, the preparation time differed widely between workshops. Part of this can be explained by the experience the researchers gained throughout the process in finding ways to link user feedback to the ontology and the prototype. For instance, workshop 5 was much more efficiently prepared than workshop 2. With regard to the execution, it is clear that the observations and the embodied system use in workshop 5 required the biggest effort of the researchers. This mainly has to do with the chosen methods, i.e., contextual inquiry and small group role-play.

Finally, we have mapped the workshops to three of the five steps defined for ontology development by Pinto and Martins (2004) to determine their main impact on the ontology creation process. However, this classification should not be interpreted too strictly, since in reality every workshop type resulted in some feedback for every stage in the ontology engineering process.

The domain experts were not included in the implementation stage, since this concerns the translation of models as, e.g., the decision tree, into an ontology language. This is unrelated to domain expertise and the goal was not to overburden the domain experts. The final step of Pinto \& Martins is also excluded from Table 2, since in our opinion the step could in practice not be distinguished from the other steps in the process. Just as the future care concepts were continuously evaluated by new iterations of the scenario in the innovation binder, the continuous care ontology was permanently maintained and adjusted in every step of the ontology creation. While Pinto and Martins reserve this phase for the last step in the ontology creation, in our case, we started maintaining and adjusting the ontology after every workshop type.

However, in respect to Table 2, we also wish to express that, while we found it important to make this comparison of the different workshops, we also wish to stress its relativity by underlining that the parameters were also determined by the experience the researchers involved had at the time and the sequential order of the workshops. It is therefore difficult to determine which workshop was most insightful, although it is clear that some workshop types were more successful in reaching their objectives than others, i.e., workshop type 3 (decision-making) and 5 (embodied system use). 
A prototype was developed to test the ontology and ensure its cross-institutional validity. While workshops 4 and 5 resulted in a lot of feedback on the prototype, it was unclear to what extent this method was also successful for validating the ontology. The lack of feedback on the ontology can be understood as a validation of the ontology, but it can also mean that the method is not suited for ontology validation. Moreover, while the prototype covered some elements of the ontology, it did not include all of them. The question remains how this method can be used to validate all elements in the ontology. Given the high time investment needed not only for organizing the workshops, but also for development and implementation of the prototype, it seems unrealistic to develop several prototypes in order to cover every element in the ontology. Additional methods should be thought out for cross-institutional ontology validation. We are currently looking into methods and tools (Power, 2011) which allow automatically translating an ontology into a natural language description of the concepts covered in the ontology. Users could read this generated story and identify incomplete or incorrect sentences. We are also looking into available tools to formally evaluate an ontology, such as OntoClean (Guarino and Welty, 2000) and AEON (Völker et al., 2008). Based on these user remarks and the results of the tools, additional workshops or prototypes could be made to fill the gaps.

The innovation binder took a central position as a project management tool. It served as a boundary object between all project partners and created a common perspective that was supported by all the involved stakeholders. Every step of the future scenario that was included in the innovation binder got translated into implications for every project partner. While this is a useful exercise, it is also an extensive one. Every insight gained during the workshops might result into changes in the scenario, which may then again have to be translated in new implications for the project partners. These continuous iterations on the scenario and its implications require a high engagement of all project partners and can only work when meetings are organized on a regular basis with a small group of engaged people.

An important challenge was to make the innovation binder both a shared vision and a tool. The information in the innovation binder had to be somewhat "visionary, but at the same time could not be too high level and had to be translatable into concrete requirements. At one time in the process, i.e., after workshop 2 , it actually seemed that the innovation binder got too high level, missed its practical use and did not deliver the expected results. Making the scenario somewhat less future oriented and more concretely linked to current practices helped to increase its usability.

\section{Conclusion: Lessons learned}

In this paper, we have described the steps we have taken in order to involve stakeholders and targeted end-users in the development of a continuous care ontology and continuous care concepts. To that aim, we have created a stakeholder group, did observations in both a care and a cure setting and organized a series of workshops that aimed to involve domain experts from the beginning, but at the same time did

Table 2

Comparing observations and the various workshop types

\begin{tabular}{|c|c|c|c|c|c|c|c|}
\hline & & Observations & $\begin{array}{l}\text { WS1 Intro } \\
\text { ontologies }\end{array}$ & $\begin{array}{c}\text { WS2 } \\
\text { Role-play }\end{array}$ & $\begin{array}{c}\mathrm{W} 3 \mathrm{a}+\mathrm{b} \\
\text { Decision-making }\end{array}$ & $\begin{array}{c}\text { WS4 Concept } \\
\text { evaluation }\end{array}$ & $\begin{array}{l}\text { WS5 Embodied } \\
\text { System use }\end{array}$ \\
\hline \multicolumn{2}{|c|}{ Number of participants } & +50 & 22 & 18 & $\begin{array}{l}\text { a) } 16 \& \\
\text { b) } 4\end{array}$ & 14 & $\begin{array}{c}7 \text { groups of } \\
2 \text { or } 3 \text { people }\end{array}$ \\
\hline \multicolumn{2}{|c|}{ Used tools } & $\begin{array}{l}\text { Mind } \\
\text { maps, } \\
\text { Document } \\
\text { Flows }\end{array}$ & $\begin{array}{l}\text { Presentation, } \\
\text { Paper-based } \\
\text { ontology } \\
\text { engineering } \\
\text { exercises }\end{array}$ & $\begin{array}{c}\text { Persona \& Context cards, } \\
\text { Storyboard, Drawings \& } \\
\text { Post-its, PRoF, Sensors } \\
\text { \& Devices, Visualized } \\
\text { ontology graph on paper }\end{array}$ & $\begin{array}{c}\text { Blueprint, } \\
\text { Post-its, } \\
\text { Pawns, Props, } \\
\text { Paper-based } \\
\text { decision trees }\end{array}$ & $\begin{array}{l}\text { Movie, } \\
\text { Poster }\end{array}$ & $\begin{array}{l}\text { Situation } \\
\text { \& Context } \\
\text { cards, } \\
\text { PRoF, } \\
\text { prototype }\end{array}$ \\
\hline Time & $\begin{array}{l}\text { Preparation } \\
\text { Duration }\end{array}$ & $\begin{array}{l}\text { Medium } \\
3 \text { Weeks }\end{array}$ & $\begin{array}{l}\text { Long } \\
1 / 2 \text { day }\end{array}$ & $\begin{array}{c}\text { Very long } \\
1 \text { day }\end{array}$ & $\begin{array}{l}\text { Short } \\
2 \text { hrs. }\end{array}$ & $\begin{array}{c}\text { Medium } \\
\text { Half a day }\end{array}$ & $\begin{array}{c}\text { Short } \\
2.5 \mathrm{hrs} . / \mathrm{session}\end{array}$ \\
\hline Main impact & $\begin{array}{c}\text { Specification } \\
\text { Conceptualization } \\
\text { Formalization }\end{array}$ & $\mathrm{x}$ & $\mathrm{x}$ & $\mathrm{x}$ & $\mathrm{x}$ & $\mathrm{x}$ & $\mathrm{x}$ \\
\hline
\end{tabular}


not require efforts that are too demanding on their part. The method actively involves ontology engineers, social scientists and stakeholders, i.e., nurses, caregivers, care receivers, doctors and professionals working for the healthcare industry, in the ontology engineering process.

It should be stressed that while this project involved ontology engineers, implementers and social scientists who have a lot of experience involving users in design processes, the thought-out process was largely experimental and all researchers involved had to creatively use the methods they were familiar with. While it is important to start from best practices with regard to the methods used, the researchers involved also had to be somewhat reckless at times in order to find a way to involve the domain experts' perspective in the creation of the ontology. We acknowledge that the process that we have followed might not be recommended at all times. Indeed, it is sometimes difficult to fully grasp the effectiveness of a workshop, or to differentiate whether a method is (un)suited or simply confirms the findings. We therefore hope that the process is inspiring and encourages other researchers to do similar experiments and adjust the methods we have used to their own needs. Next, the most important lessons learned are discussed.

Creating common ground: A step that is elementary is creating common ground with the stakeholders involved in the workshops. There was some discussion to what extent the users should understand the full complexity of the project and ontology when participating in a workshop. While reaching common ground was explicitly the aim of workshop 1, we somewhat overlooked the importance of this aspect when involving a larger group of stakeholders in workshop 4, and as a result this workshop resulted in discussions that were similar to the ones we had in workshop 1. Consequently, a far more elaborate introduction was included in workshop 5, with better results.

Elicitate out-of-the-box thinking: Reserving sufficient introductory time is not only important for creating common ground, but also to facilitate the participants to move from thinking about current practices to future ones. At first, participants might be overwhelmed or amazed by the possibilities of a new system or contrary fiercely opposed to the idea of installing automated processes. It takes some time to overcome those first ideas, get insight in the reasons for their initial enthusiasm or aversion and stimulate creative thinking that goes beyond current practice, but still takes into account the particularities of the environment and the users. It was evident that simply bringing the stakeholders together with stakeholders from other disciplines was not sufficient to help the participant make this transition and think out-of-the-box. To this aim, it is also important to provide the right tools. For instance, immersive tools such as the persona and situation cards used in workshops 2 and 5 served as good elicitation tools as it took stakeholders out of there usual role and context. The movie used in workshop 4 was on the contrary a more distant, detached experience and thus resulted in less creative thinking.

Getting the group size right: Finding the right group size is a challenge and depends on the aim of the workshop. While in workshop 1, the large size of the group was not a disadvantage since the aim was mainly to create common ground, a large group did become a problem when in-depth feedback was wanted. The series of small-sized workshops of type 5 where very labor intensive, but the participants were more critical and gave more detailed feedback. This of course had also to do with the fact that the workshop gave them a deeper experience of the system.

Reaching consensus: At times in the process, particularly after workshop 2, the lack of consensus among the participants was worrying for the research team. However, workshop 3 made clear that this lack of consensus is actually an indication that the ontology should consider not including the concept in the high-level ontology. If the interpretations of a concept are dispersed, it might be best to move it to a low-level ontology or exclude it.

Working in interdisciplinary teams: Throughout the whole process, both social scientists and ontology engineers were involved in the process. This mixture had as advantage that both the user and technical perspective were at the forefront in all stages of the ontology construction. Not only during the development of the method and practicalities of the workshop all parties were present, but also during the workshops themselves and during analysis. This facilitated the translation of user findings to the ontology and innovation binder. The innovation binder in particular proved to be a powerful tool in this project in bringing together future continuous care concepts, and user and technical requirements. However, the tool would not have been successful if not supported by all parties involved. 
Connecting ontology engineers and stakeholders: One of the challenges during the workshops was the facilitation of the communication between the ontology engineers and stakeholders. It became apparent that bridges needed to be built between them. This was done in various ways. First, the ontology engineers took part in the observations to get an idea of the current work practices of the stakeholders. Second, bridges were also used during the workshops, e.g., the storyboard in workshop 2 or the decision tree in workshop 3. Finally, the resulting ontology and axioms were communicated with the stakeholders in easily understandable formats, e.g., document workflows, mind maps, graphs and decision trees. We noted that some ways of building bridges were more successful than others. Mutual interaction seems to be key. In Workshop 2 there was limited interaction between the ontology engineers and the other stakeholders. Ontology engineers observed the others' work but stakeholders tended to forget to comment on the conceptual graph under construction. The stakeholders became oblivious of the ontology engineers' task and ontology engineers could not get feedback on the model as it was being constructed.

Timing: One of the goals was to achieve user participation beyond collecting the requirements of the ontology in the specification phase, but without actually pushing them in the role of ontology engineers and thus overburdening them. The stakeholders are mainly involved through the workshops and observations. The observations comprised of 1 week in each continuous care setting, during which staff members were followed and interviewed. The workshops lasted 2 to 3 hours on average. The workshops were distributed amongst the available participants, while maintaining the group of each workshop representative of the different stakeholders in the domain. Participants often remarked that the sessions seemed too short to get to the bottom of the issue at hand. However, it was difficult to lengthen the workshops as participants often could not make themselves available that long. In line with a suggestion of one of the participants, a follow-up session was coupled with each workshop in which the output of the workshop and the achieved results are presented. This permits to briefly discuss pressing issues not handled during the workshop, to evaluate the output and to illustrate to the stakeholders that their input was taken into account and that is was time well spent. It was also concluded that while the described approach limits the time that has to be invested by the stakeholders, it does require a large amount of time and effort from the social scientists and ontology engineers.

Learning by doing: A hands-on approach was used during the workshops, e.g., exercises in workshop 1, role-playing in workshop 2 and 5 and question-and-answer process in workshop 3. Participants were also stimulated to reflect on sometimes highly complex issues. It was found that participants much appreciated this approach of action and reflection. It allowed them to reflect on their current practices, enhanced their understanding of the topic and elicited discussion.

Getting the language right: At the start of the project, the question was put forth in which language the ontology should be created: Dutch (the mother language of the stakeholders) or English. Clearly each option has benefits. Dutch would make it easier to let stakeholders evaluate the ontology. It does not require command of a foreign language and may more easily invoke intuitive understanding. Furthermore, words used within the domain of interest could be inserted directly into the ontology. An English ontology, however, would make it easier to reuse existing ones and to reach an international audience. Also, the search for an appropriate translation would force stakeholders to have a thorough discussion of what the concept means to them and facilitate a truly shared understanding. Ultimately, we chose to have the best of both 'ontologies' by making the ontology in English and annotating it in Dutch.

In future research, we are exploring if and how the current ontology for institutionalized care and cure can be extended to non-institutionalized care or home care. Other prototypes are also being developed using this continuous care ontology to evaluate its completeness and validity. We also will investigate whether this research process can be repeated by engineers who are less knowledgeable about ontologies. Ontology engineers are currently relatively rare and therefore it would be interesting to see to what extent our method is easily reproducible and what the thresholds are. 


\section{Acknowledgements}

Part of this research was supported by the iMinds ICON Project ACCIO. This project is co-funded by IWT, iMinds and the following partners: Televic Healthcare NV, Boone NV, Dominiek Savio Instituut and In-Ham. F. Ongenae would like to thank the IWT for financial support through her Ph.D. grant. Several workshops were organized in the PRoF demo rooms located in Poperinge, Belgium. We thank all the participants in ACCIO for their valuable contribution to the project.

\section{References}

Auer, S., and Herre, H. (2007). RapidOWL - an Agile Knowledge Engineering Methodology, In Proc. of the 6th International Andrei Ershov Memorial Conference, Novosibirsk, Russia, 424-430.

Bachman, C., and Daya, M. (1977). The role concept in data models, In Proc. of the 3rd International Conference on VLDB, 464-476.

Barnaghi, P., Compton, M., Corcho, O., Castro, R. G., Braybeal, J., Herzog, A., Janowicz, K., Neuhaus, H., Nikolov, A., and Page, K. (2011). Semantic Sensor Network XG Final Report, W3C Incubator Group Report. Available at: http: //www . w3.org/2005/Incubator/ssn/XGR-ssn-20110628/.

Bassetti, C. (1012). Chapter 16 on IS-related organizational change and the necessity of techno-organizational co-design(in-use). An experience with ethnomethodologically oriented ethnography, Phenomenology, Organizational Politics, and IT Design: The Social Study of Information Systems, Viscusi, G., Campagnolo, G. M., and Curzi, Y. (eds), Hershey, Penn.: IGI Global, 289-310.

Beyer, H. and Holtzblatt, K. (1997). Contextual Design: Defining Customer-Centered Systems, Morgan Kaufmann Publishers Inc., San Francisco, USA.

Blake, J. A., and Harris, M. A. (2008). The Gene Ontology (GO) project: structured vocabularies for molecular biology and their application to genome and expression analysis, Current Protocols in Bioinformatics, 23(7.2.1-7.2.9), 1472-6947. Available at: http://www. geneontology.org/.

Bleumers, L., Sulmon, N., Ongenae, F., Jacobs, A., Verstraete, M., Van Gils, M., Ackaert, A., and De Zutter, S. (2011). Towards ontology co-creation in institutionalized care settings, In Proc. of the 5th International Conference on Pervasive Computing Technologies for healthcare (PervasiveHealth), Dublin, Ireland.

Boone International, the wallbed specialist (Last visited February 2013). http: / / www . boone-wal lbeds.com/.

Burgelman, J.-C., and Punie Y. (2006). Close encounters of a different kind: ambient intelligence in Europe, True Vision: The Emergence of Ambient Intelligence, 19-35.

Copeland, M., Brown, A., Parkinson, H., Stevens, R., and Malone, J. (2012). The SWO Project: A Case Study of Applying Agile Ontology Engineering Methods in Community Driven Ontologies, In Proc. of the International Conference on Biomedical Ontology (ICBO), Graz, Austria.

Dominiek Savio Institute vzw (Last visited February 2013). http: / /www . dominiek-savio.be/

Fan, J., Barker, K., Porter, B., and Clark, P. (2001). Representing Roles and Purpose, In Proc. of the International Conference on Knowledge Capture (K-Cap), Victoria, British Columbia, Canada, 38-43.

Fernández, M. , Gómez-Pérez, A. and Juristo, N. (1997). METHONTOLOGY: from ontological art towards ontological engineering, In Proc. of the American Asociation for Artificial Intelligence (AAAI) Spring Symposium Series on Ontological Engineering, Stanford, USA, 33-40.

Fook, V. F. S., Tay, S. C., Jayachandran, M., Biswas, J., Zhang, D. (2006). An ontology-based context model in monitoring and handling agitation behaviour for persons with dementia, In Proc. of the 4th IEEE International Conference on Pervasive Computing and Commununications Workshops (PERCOMW), Pisa, Italy, 560-564.

Gangemi, A., Borgo, S., Catenacci, C., and Lehman, J. (2005). Task taxonomies for knowledge content (deliverable D07), Laboratory for Applied Ontology (LOA), 9-26. Available at: http://www.loa.istc.cnr.it/Papers/D07_v21a. pdf.

Gomez-Perez, A., Corcho, O. and Fernandez-Lopez, M. (2003). Ontological Engineering: with examples from the areas of Knowledge Management, e-Commerce and the Semantic Web, Springer-Verlag, London, UK.

Grenning, J. (2002). Planning poker or how to avoid analysis paralysis while release planning. Available at: http:// renaissancesoftware. net/files/articles/PlanningPoker-v1.1.pdf.

Gruber, T. (1993). A translation approach to portable ontology specifications, Knowledge Acquisition, 5, 199-220.

Grüninger, M. and Fox, M. (1995). Methodology for the design and evaluation of ontologies, In Proc. of the International Joint Conference on Artificial Intelligence, Workshop on Basic Ontological Issues in Knowledge Sharing, Montreal, Canada.

Guarino, N., and Welty, C. A. (2000). A formal ontology of properties, In Proc. of the 12th European Workshop on Knowledge Acquisition, Modeling and Management, Juan-les-Pins, France, 97-112.

Horrocks, I., Patel-Schneider, P. F., Boley, H., Tabet, S., Grosof, B., and Dean, M. (2004). SWRL: A Semantic Web Rule Language Combining OWL and RuleML, W3C Member Submission. Available at: http://www.w3.org/Submission/ SWRL/.

Kensing, F., and Blomberg, J. (1998). Participatory Design: Issues and Concerns, Computer Supported Cooperative Work, 7(3-4), $167-185$ 
Knublauch, T. H., Fergerson, R. W., Noy, N. F., Musen, M. A. (2004). The Protégé OWL Plugin: An Open Development Environment for Semantic Web Applications, In Proc. of the 3rd International Semantic Web Conference, Hiroshima, Japan, 229-243. Available at: http://protege. stanford.edu/.

Ko E. J., Lee H. J., Lee J. W. (2007). Ontology-based context modeling and reasoning for U-HealthCare, Transactions on Information and Systems, $\mathbf{E ( 9 0 ) - D ( 8 ) , 1 2 6 2 - 1 2 7 0 . ~}$

Kotis, K. and Vouros, G.A. (2006). Human-centered ontology engineering: The HCOME methodology, International Journal of Knowledge and Information Systems (KAIS), 10, 109Ü-131.

Kuziemsky, C. E., and Lau, F. (2010). A four stage approach for ontology-based health information system design, Artificial Intelligence in Medicine, 50(3), 133-148.

Martensson, P., and Lee, A. S. (2004). Dialogical Action Research at Omega Corporation, Management Information Systems Quarterly, 28(3), 507-536.

Martin, D., Burstein, M., Hobbs, J., Lassila, O., McDermott, D., McIlraith, S., Narayanan, S., Paolucci, M., Parsia, B., Payne, T., Sirin, E., Srinivasan, N., Sycara, K. (2004). OWL-S: Semantic Markup for Web Services, W3C Member Submission. Available at: http://www.w3.org/Submission/OWL-S/.

Martin, R. (2002). Agile Software Development, Principles, Patterns and Practices, Prentice Hall.

Mascardi, V., Cordi, V. and Rosso, P. (2006). A Comparison of Upper Ontologies, Technical Report DISI-TR-06-21. Available at: http://www.disi.unige.it/person/MascardiV/Download/DISI-TR-06-21.pdf.

McGuinnes, D. L., and Van Harmelen, F. (2004). OWL Web Ontology Language overview, W3C Recommendation. Available at: http: //www.w3.org/TR/2004/REC-owl-features-20040210.

Miller, E. T., Deets, C., and Miller, R. (1997). Nurse call and the work environment: lessons learned, J Nurs Care Qual, 15(3), $7-15$.

O'Connor, M. J., and Das, A. K. (2010). A lightweight model for representing and reasoning with temporal information in biomedical ontologies, In Proc. of the International Conference on Health Informatics (HEALTHINF), Valencia, Spain, 90-97.

OLV Hospital Aalst (Last visited February 2013). http: / / www . olvz . be /

Ongenae, F., Ackaert, A., Jacobs, A., Veys, A., Van Gils, M., Verhoeve, P. and De Turck, F. (2010). User-driven design of an ontology-based ambient-aware continuous care platform, In Proc. of the 4th International Conference on Pervasive Computing Technologies for Healthcare, Munich, Germany, 1-4.

Ongenae, F., Bleumers, L., Sulmon, N., Verstraete, M., Van Gils, M., Jacobs, A., De Zutter, S., Verhoeve P., Ackaert, A., and De Turck, F. (2011). Participatory design of a continuous care ontology: towards a user-driven ontology engineering methodology, In Proc. of the International Conference on Knowledge Engineering and Ontology Development (KEOD), Paris, France, $81-90$

Ongenae, F., Claeys, M., Dupont, T., Kerckhove, W., Verhoeve P., Dhaene, T., and De Turck, F. (2013). A Probabilistic Ontologybased Platform for Self-learning Context-aware Healthcare Applications, Expert Systems with Applications, 40(18), 76297646.

Ongenae, F., De Backere, F., Steurbaut, K., Colpaert, K., Kerckhove, W., Decruyenaere, J., and De Turck, F. (2011). Appendix $\mathrm{B}$ : overview of the existing medical and natural language ontologies which can be used to support the translation process, BMC Medical Informatics and Decision Making, 10(3), 4.

Ongenae, F., Duysburgh, P., Verstraete, M., Sulmon, N., Bleumers, L., Jacobs, A., Ackaert, A., De Zutter, S., Verstichel, S., and De Turck, F. (2012). User-driven design of a context-aware application: an ambient-intelligent nurse call system, In Proc. of the User-Centered Design of Pervasive Healthcare Applications Workshop (U-CDPHA) of the 6th International Conference on Pervasive Computing Technologies for healthcare (PervasiveHealth), San Diego, CA, USA, 6.

Ongenae, F., Myny, D., Dhaene, T., Defloor, T., Van Goubergen, D., Verhoeve, P., Decruyenaere, J., and De Turck, F. (2011). An ontology-based nurse call management system (oNCS) with probabilistic priority assessment, BMC Health Services Research, 11, 28.

Paganelli, F., Giuli, D. (2011). An ontology-based system for context-aware and configurable services to support home-based continuous care, IEEE Transactions on Information Technology in Biomedicine, 15(2), 324-333.

Pinto, H. and Martins, J. (2004). Ontologies: how can they be built?, Knowledge and Information Systems, 6(4), 441 Ú-464 $^{-4}$

Power, R. (2011). Deriving rethorical relationships from semantic content, In Proc. of the 13th European Workshop on Natural Language Generation (ENLG), Nancy, France, 82-90.

PRoF Consortium (Last visited February 2013). PRoF: Patient Room of the Future, http: / / www . prof-projects. com/.

Pruitt, J., and Adlin, T. (2006). The persona lifecycle: keeping people in mind throughout product design, Morgan Kaufmann, San Mateo, USA.

Punie Y. (2005). The future of ambient intelligence in Europe: the need for more everyday life, Comm Strat, 57, 141-165.

Rector, A. L., Rogers, J. E., Zanstra, P. E., and van der Haring, E. (2003). OpenGALEN: Open Source Medical Terminology and Tools, In Proc. of the annual American Medical Informatics Association (AMIA) Symposium, Washington, DC, USA, 982. Available at: http://www.opengalen.org/.

Roy, N., Gu, T. and Das, S. K. (2010). Supporting pervasive computing applications with active context fusion and semantic context delivery, Pervasive and Mobile Computing, 6(1), 21-42.

Sanders, E., and Stappers, P. J. (2008). Co-creation and the new landscapes of design, Co-design, 4, 5-18.

Satyanarayanan, M. (2001). Pervasive Computing: Vision and Challenges, IEEE Personal Communications, 8(4), 10-17.

Schuler, D., and Namioka, A. (1993). Participatory Design: Principles and Practices, CRC/Lawrence Erlbaum Associates, Hillsdale, NJ, USA.

Semantics Utilised for Process management within and between EnteRprises (SUPER Ontologies) (Last visited February 2013). http://www.ip-super.org/content/view/129/136/.

Simperl, E., Mochol, M. , Bürger T. and Popov, I. O. (2010). Achieving Maturity: the State of Practice in Ontology Engineering in 2009, International Journal of Computer Science and Applications, 7(1), 45-65. 
Motik, B., Shearer, R., Horrocks, I. (2009). Hypertableau Reasoning for Description Logics, Journal of Artificial Intelligence Research, 36, 165-228. Available at: http://pellet. owldl.com/.

Smith, E., and Medin, D. (1981). Categories and Concepts, Harvard University Press, Cambridge, MA

Spyns, P., Tang, Y. and Meersman, R. (2008). An ontology engineering methodology for DOGMA, Applied Ontology, 3(1-2), 13-39.

Star, S. L., and Griesemer, J. R. (1989). Institutional Ecology, 'Translations' and Boundary Objects: Amateurs and Professionals in Berkeley's Museum of Vertebrate Zoology, 1907-39, Social Studies of Science, 19(3), 387-420.

Steimann, F. (2007). The role data model revisited, Applied Ontology, 2(2), 89-103.

Sunagawa, E., Kozaki, K., Kitamura, Y., and Mizoguchi, R. (2004). Organizing role-concepts in ontology development environment: Hozo, AI Technical Report, 1(4), 453-468.

Sure, Y., Staab, S. and Studer, R. (2009). Handbook on Ontologies, Chapter on Ontology Engineering Methodology, International Handbooks on Information Systems, Springer, Berlin-Heidelberg, 135-152.

Televic Healthcare (Last visited February 2013). http: / / www . televic-healthcare.com/en/.

Tentori, M., Segura, D. and Favela, J. (2009). Mobile Health Solutions for Biomedical Applications, chapter VIII: Monitoring hospital patients using ambient displays, Medical Information Science Reference, USA.

The ACCIO Project (2012). http://www.iminds.be/en/research/overview-projects/p/detail/ accio-2.

The Business Management Ontology (BMO) (Last visited February 2013). http://www.bpiresearch.com/ Resources/RE_ossont/re_ossont.htm.

The DEUS Project, Design and Easy Use of wireless Services (2010). http://www.iminds.be/en/research/ overview-projects/p/detail/deus.

The Family SWRL Ontology (Last visited February 2013). http://protege.cim3.net/file/pub/ontologies/ family.swrl.owl/family.swrl.owl.

The Process Ontology (Last visited February 2013). http://en.wikipedia.org/wiki/Process_ontology.

The Process Specification Language (PSL) (Last visited February 2013). http://www.mel.nist.gov/psl/index. html.

Uschold, M. and King, M. (1995). Towards a methodology for building ontologies, In Proc. of the International Joint Conference on Artificial Intelligence, Workshop on Basic Ontological Issues in Knowledge Sharing, Montreal, Canada.

Valls, A., Gibert, K., Sánchez, D., Bateta, M. (2010). Using ontologies for structuring organizational knowledge in Home Care assistance, International Journal of Medical Informatics, 79(5), 370-387.

Verstichel, S., De Poorter, E., De Pauw, T., Becue, P., Volckaert, B., De Turck, F., Moerman, I., and Demeester, P. (2010). Distributed ontology-based monitoring on the IBBT WiLab.t infrastructure, In Proc. of the 6th International Conference on Testbeds and Research Infrastructures for the Development of Networks and Communities (TridentCom), Berlin, Germany, $509-525$.

Völker, J., Vrandečić, D., Sure, Y., Hotho, A. (2008). AEON - An approach to the automatic evaluation of ontologies, Applied Ontology, 3(1-2).

XMind, Professional \& Powerful Mind Mapping Software (Last visited February 2013). http: //www . xmind. net/.

Zhang, D., Yu, Z., Chin, C. Y. (2005). Context-aware infrastructure for personalized healthcare, Studies in Health Technology and Informatics, 117, 154-163. 